\title{
Airborne Shaped Sonic Boom Demonstration Pressure Measurements with Computational Fluid Dynamics Comparisons ${ }^{* \dagger}$
}

\author{
Edward A. Haering, Jr .", James E. Murray ${ }^{\S}$, and Dana D. Purifoy ${ }^{* *}$ \\ NASA Dryden Flight Research Center, Edwards, CA, 93523-0273 \\ David H. Graham ${ }^{\dagger \dagger}$ and Keith B. Meredith \\ Northrop Grumman Corporation, Integrated Systems Division, El Segundo, CA, 90245 \\ Christopher E. Ashburn ${ }^{\S \S}$ \\ Analytical Services \& Materials, Inc., Edwards, CA, 93523-0273 \\ and \\ Lt. Col. Mark Stucky ${ }^{* * *}$ \\ U.S. Air Force Test Pilot School, Edwards, CA, 93524
}

\begin{abstract}
The Shaped Sonic Boom Demonstration project showed for the first time that by careful design of aircraft contour the resultant sonic boom can maintain a tailored shape, propagating through a real atmosphere down to ground level. In order to assess the propagation characteristics of the shaped sonic boom and to validate computational fluid dynamics codes, airborne measurements were taken of the pressure signatures in the near field by probing with an instrumented F-15B aircraft, and in the far field by overflying an instrumented L-23 sailplane. This paper describes each aircraft and their instrumentation systems, the airdata calibration, analysis of the near- and far-field airborne data, and shows the good to excellent agreement between computational fluid dynamics solutions and flight data. The flights of the Shaped Sonic Boom Demonstration aircraft occurred in two phases. Instrumentation problems were encountered during the first phase, and corrections and improvements were made to the instrumentation system for the second phase, which are documented in the paper. Piloting technique and observations are also given. These airborne measurements of the Shaped Sonic Boom Demonstration aircraft are a unique and important database that will be used to validate design tools for a new generation of quiet supersonic aircraft.
\end{abstract}

\footnotetext{
* Note that the use of trade names or names of manufacturers in this document does not constitute an official endorsement of such products or manufacturers, either express or implied, by the National Aeronautics and Space Administration.

$\dagger$ This material is declared a work of the U.S. Government and is not subject to copyright protection in the United States.

* Aerospace Engineer, Research Aerodynamics, MS 2228, PO Box 273, AIAA nonmember.

$\S$ Aerospace Engineer, Research Aerodynamics, MS 2228, PO Box 273, AIAA nonmember.

${ }^{* *}$ Research Test Pilot, Flight Operations, MS 2802, PO Box 273, AIAA nonmember.

${ }^{\dagger}$ Lead SSBD Aerodynamics Engineer, Flight Sciences, 9V11/W6, AIAA member.

\#SBD CFD Lead, Flight Sciences, 9V11/W6, AIAA nonmember.

$\S \S$ Meteorologist, Research Aerodynamics, MS 2228, PO Box 273, AIAA nonmember.

*** Chief, Test Management, 220 S. Wolfe Avenue, AIAA nonmember.
} 


\section{Nomenclature}

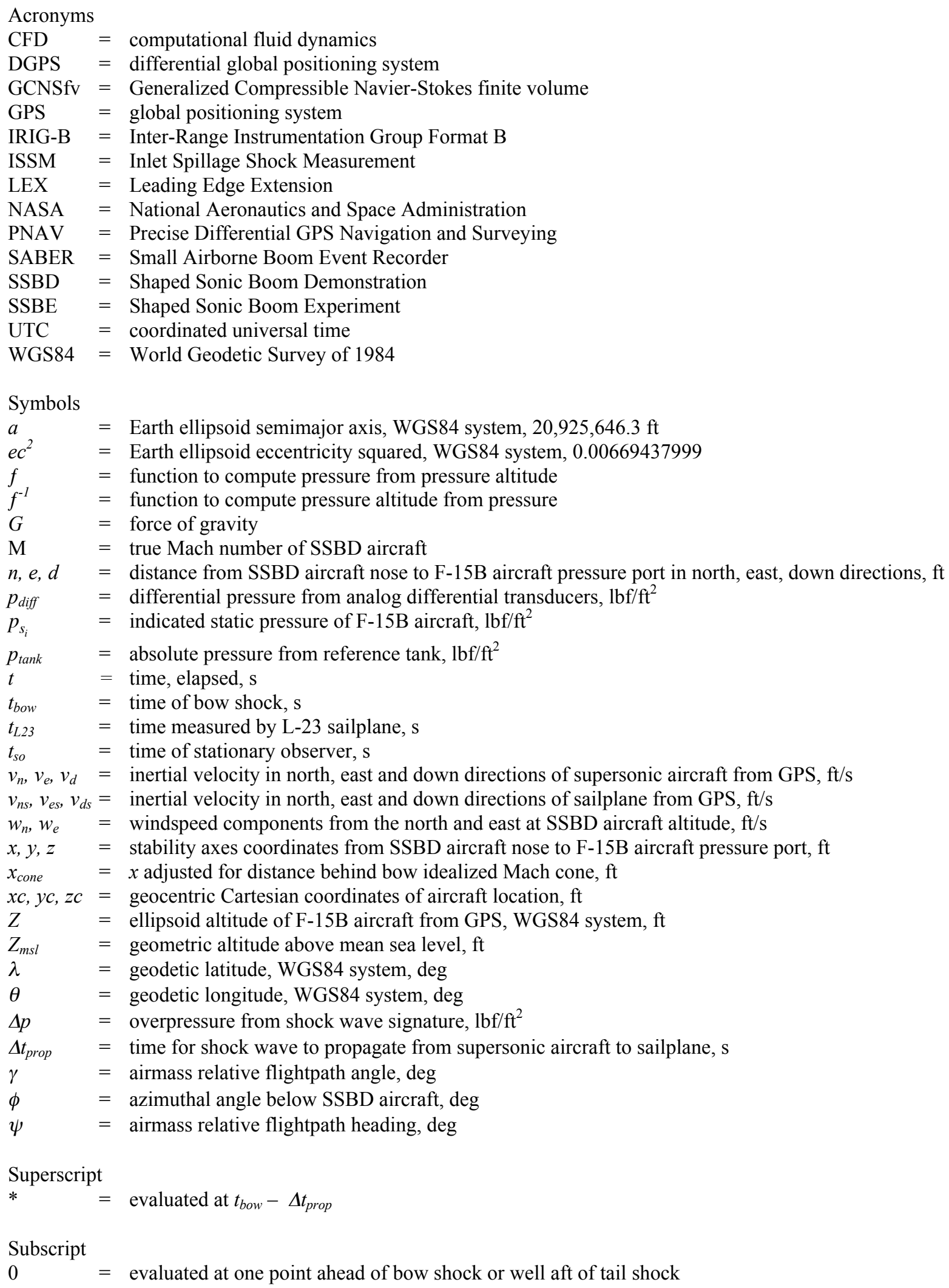




\section{Introduction}

$\mathrm{T}$

HE Shaped Sonic Boom Demonstration (SSBD) project sought to validate the theory ${ }^{1-6}$ that aircraft shaping could provide a shaped sonic boom to the ground, a first step in producing supersonic aircraft with reduced sonic booms. Figure 1 shows the Northrop Grumman SSBD aircraft, ${ }^{7}$ which is a modified U.S. Navy F-5E aircraft and which on August 27, 2003 provided the world's first flight demonstration of a shaped sonic boom from an aircraft through an actual atmosphere down to the ground. Figure 2 shows the world's first ground-level shaped sonic boom recording and a baseline F-5E aircraft N-wave. An unmodified baseline F-5E aircraft flew $45 \mathrm{~s}$ behind the SSBD aircraft so the effect of the aircraft modification could be more clearly seen. The baseline F-5E aircraft produced the classic N-wave sonic boom shape, while the SSBD aircraft had a reduced initial shock, clipping the peak off the N-wave. This shaped sonic boom result was repeated on many flights on many different days. ${ }^{8}$ Shock waves are categorized into two components, shock caused by lift and shock caused by volume. Since the two aircraft were at nearly the same weight and therefore had nearly the same total lift, any sonic boom signature differences were due solely to volume distribution differences.

In addition to a large array of ground-level microphones and pressure sensors, ${ }^{8}$ two airborne platforms were used to measure the sonic boom signatures in the near and far field. The airborne measurement techniques for the SSBD program were inspired by and improved upon similar measurements of the SR-71 sonic boom signatures made for the High Speed Civil Transport project in 1995. ${ }^{9}$ An unmodified F-5E aircraft had near-field sonic boom signatures measured by the National Aeronautics and Space Administration (NASA) Dryden Flight Research Center F-15B aircraft for the Inlet Spillage Shock Measurement (ISSM) test in $2002,{ }^{10}$ as a precursor to the SSBD project. For the current effort, a NASA Dryden F-15B aircraft probed 60 to $720 \mathrm{ft}$ from the SSBD aircraft on six flights, resulting in 68 highly-detailed signatures. The SSBD aircraft was flown in supersonic stabilized flight, while the F-15B aircraft flew behind, below, and at times to the side in formation flight, slowly moving fore and aft to probe the pressure signature of the SSBD aircraft. The F-15B aircraft was instrumented with a special sonic boom probing noseboom, sensitive pressure instrumentation, and a carrier-phase differential global positioning system (DGPS) receiver. The DGPS data from each aircraft were differenced to give relative positions during the probings.

There were two phases of flights with the SSBD aircraft. The first phase, called the Shaped Sonic Boom Demonstration, was flown in August of 2003, during which two probing flights were performed by the F-15B aircraft. The second phase, called the Shaped Sonic Boom Experiment (SSBE), was flown in January of 2004, during which four probing flights were accomplished by the F-15B aircraft.

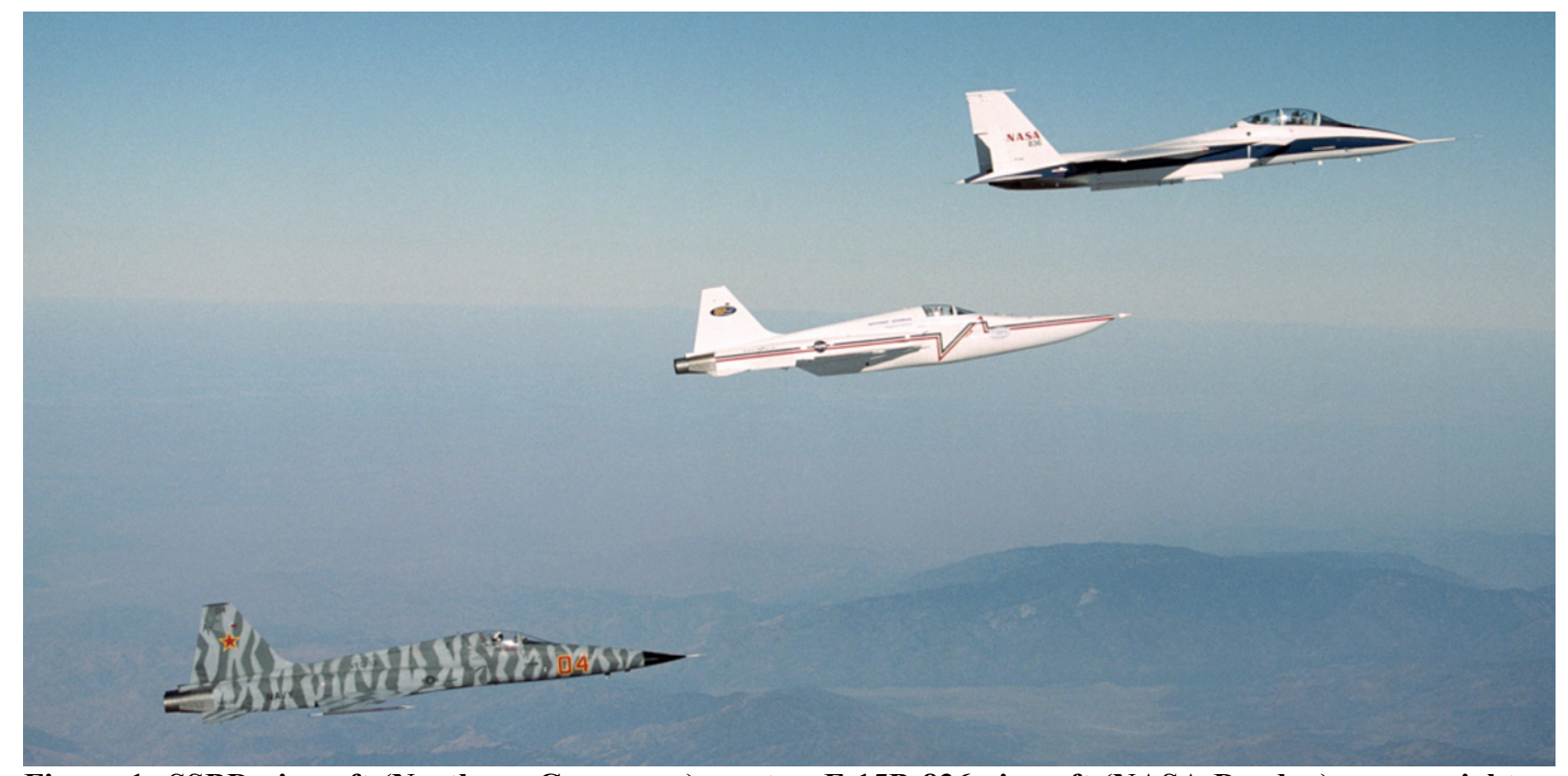

Figure 1. SSBD aircraft (Northrop Grumman), center, F-15B-836 aircraft (NASA Dryden), upper right, baseline F-5E (U.S. Navy Fallon NAS), lower left. 


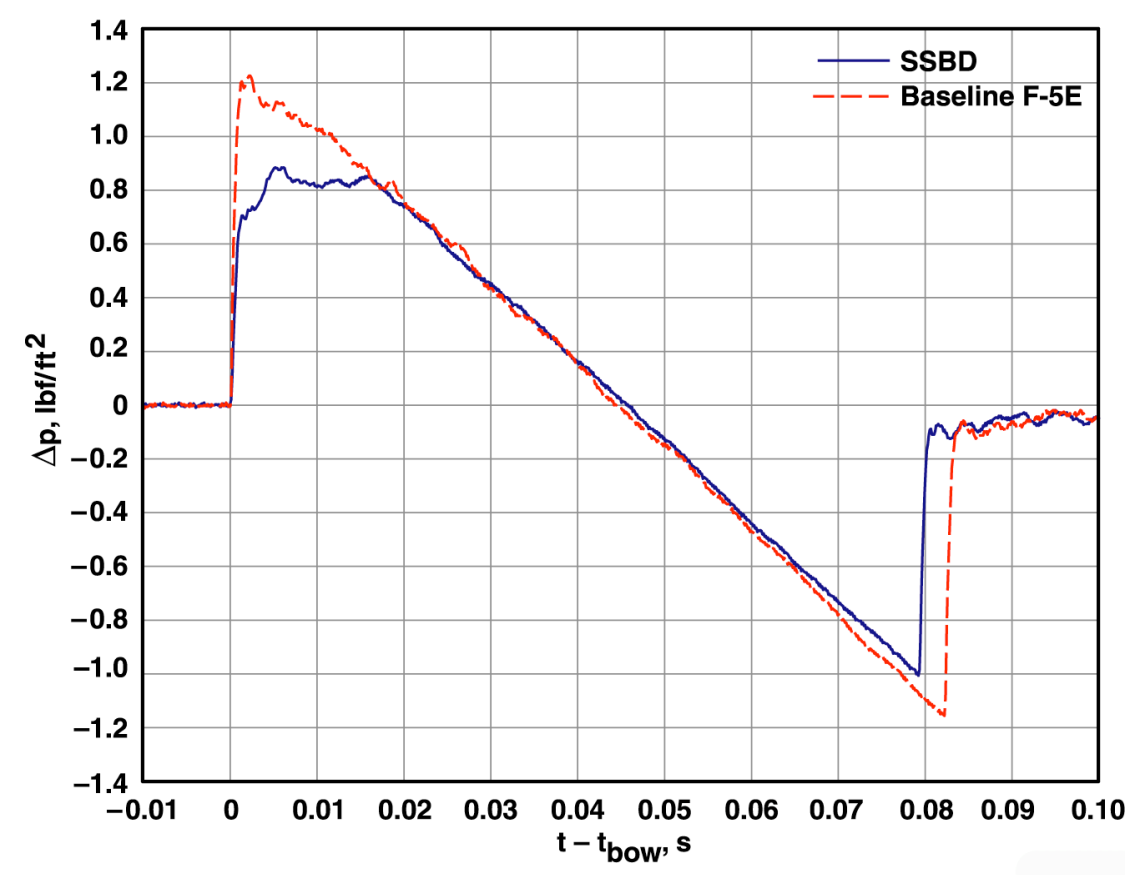

Figure 2. World's first ground-level shaped sonic boom recording in blue, baseline $\mathrm{F}-5 \mathrm{E}$ N-wave in red. SSBD flight 9, August 27, 2003.

Figure 3 shows the U. S. Air Force Test Pilot School Super Blanik L-23 sailplane that was outfitted with a sensitive microphone on the port wingtip for the SSBE flight phase. The L-23 sailplane was flown at 6,000 and $8,000 \mathrm{ft}$ above the ground, recording the sonic boom signatures as the SSBD aircraft flew overhead on $13 \mathrm{flights.}$ Sonic boom signatures that had hit the ground and reflected back up to the L-23 sailplane were also measured, as well as signatures from the baseline F-5E aircraft.

The near-field sonic boom signatures measured in flight can be used to validate the computational fluid dynamics (CFD) codes used to design low sonic boom aircraft. The Northrop Grumman-proprietary Generalized Compressible Navier-Stokes finite volume (GCNSfv) code ${ }^{11}$ was used with a grid of approximately 17.1 million points in order to properly match the flight data. Since the near-field probing did not occur perfectly level and straight, the actual relative separation path between the SSBD and F-15B aircraft was used in the CFD solution to determine a CFD-derived sonic boom signature to compare with the flight data. The calculated near-field sonic boom signature can then be used as an input to sonic boom propagation codes to predict ground-level sonic boom signatures, and these can be verified with the measured ground-level sonic booms. These validated codes can then be used with confidence to design other aircraft with shaped sonic booms.

In order to process the airborne sonic boom signature data, and also to determine the SSBD aircraft flight conditions for the CFD solutions, the SSBD aircraft airdata system was calibrated. Carrier-phase DGPS data was used with atmospheric data to provide reference airdata quantities, and a static source position error was determined as a function of Mach number to an extremely high accuracy. Pneumatic lag was significant during unsteady flight. Ground tests were performed to correct lag effects for unsteady data.

This paper describes each of the aircraft and their instrumentation systems, the airdata calibration effort, the process of analyzing the near- and far-field airborne data, and makes comparisons of CFD solutions to the flight data. The flights of the SSBD aircraft occurred in two phases with four months between phases. Problems were encountered with some of the instrumentations systems for the first phase. Corrections and improvements were made to the instrumentation system for the second phase, which are documented in the paper. Piloting technique and observations are also given. These airborne measurements of the SSBD aircraft are a unique and important database that will be used to validate design tools for a new generation of quiet supersonic aircraft. 


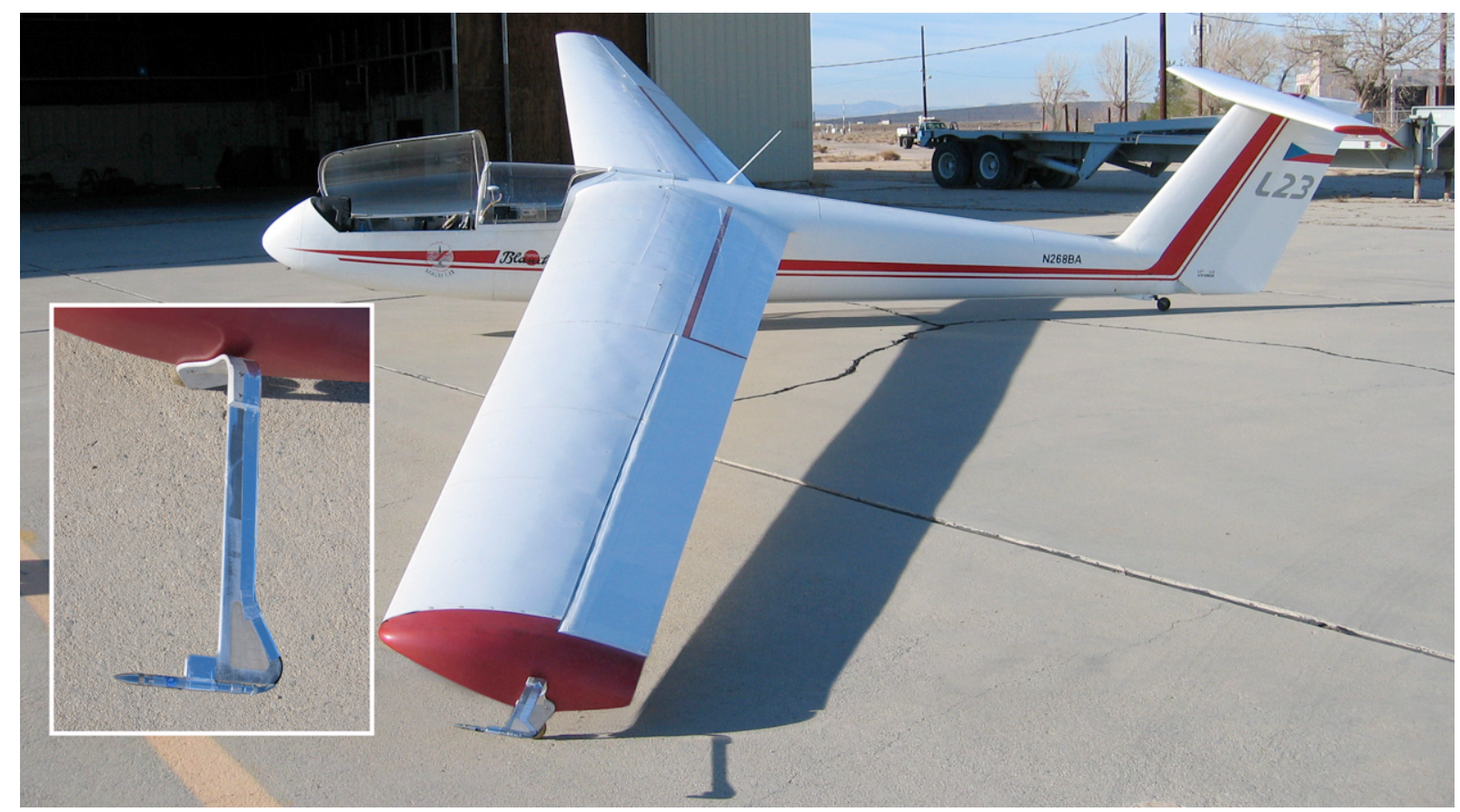

\section{Figure 3.U.S. Air Force Test Pilot School Super Blanik L-23 sailplane with wingtip-mounted microphone; closeup of microphone shown in inset.}

\section{System Descriptions}

The three main aircraft of this project will now be described, including the instrumentation required to measure the airborne pressure signatures. Atmospheric data was also gathered with balloon-borne sensors, and these are also described.

\section{A. The Shaped Sonic Boom Demonstration Aircraft}

The SSBD aircraft, ${ }^{7}$ Fig. 1, is a U.S. Navy F-5E aircraft modified by the Northrop Grumman Corporation to produce a strong bow shock with a relatively flat pressure distribution back to the engine inlet, which results in a shaped signature at ground level, reducing the front portion of the typical $\mathrm{N}$-wave signature. These modifications were tailored for the point design condition of Mach 1.4 and a pressure altitude of 32,000 ft. To determine flight conditions, the aircraft was outfitted with sensors for total and static pressure, total temperature, pitch, roll, and yaw angles and their rates, and an Ashtech (now Thales Navigation, Santa Clara, California) Z-12 carrier-phase DGPS receiver. A telemetry system was installed to transmit the pressure, temperature, attitude and angular rate data to the ground during envelope expansion flights. The DGPS receiver recorded its own raw data, and the other parameters were recorded with an onboard tape recorder, along with Inter Range Instrumentation Group Format B (IRIG-B) ${ }^{12}$ -formatted time from a time code generator initiated prior to flight with a global positioning system (GPS)-based time code generator. Cockpit video, voice, and time were also recorded for instrument panel information. Pilot reports of fuel quantity during the flight were used to infer weight and angle of attack. A handheld GPS receiver was installed in the cockpit to provide position and time-over-target predictions.

For real-time ground displays of the relative positions of the SSBD and F-15B aircraft, the SSBD aircraft GPS real-time data was transmitted over an ultra high frequency (UHF) radio. This was separate from the telemetry data stream of the SSBD aircraft.

\section{B. The F-15B Near-field Probing Aircraft}

The NASA F-15B aircraft, tail number 836, Fig. 1, is a two-seat fighter-trainer version of the F-15 air-superiority fighter built by McDonnell Aircraft (now the Boeing Company, Chicago, Illinois). It has been converted from a U.S. Air Force fighter to a research test bed aircraft with the installation of research instrumentation, recording, telemetry, and video systems, all time-tagged with GPS-based IRIG-B time. For the 
SSBD project a specialized sonic-boom-measuring noseboom was added, along with extra pressure sensors. The F$15 \mathrm{~B}$ aircraft also has a Z-12 carrier-phase DGPS receiver, and these real-time data are included in the F-15B aircraft telemetry system.

Research aircraft like the F-15B aircraft typically employ a long noseboom to measure airdata quantities that are closer to the freestream values than the fuselage-mounted sensors typical of production vehicles. This allows airdata calibrations that are generally only affected by one or two parameters, have smaller gradients, and are more sensitive than production airdata systems. The noseboom, which was used for probing the aircraft pressure signatures for this program, has total and static pressure ports that feed dedicated temperature-controlled digital absolute pressure transducers. Dedicated sensors are important to minimize pneumatic lag. The pressure instrumentation used on the F-15B aircraft during the three flight phases of this program are shown in Table 1.

Table 1. F-15B aircraft pressure instrumentation.

\begin{tabular}{|c|c|c|c|c|c|}
\hline Flight phase & $\begin{array}{l}\text { Shock-measuring } \\
\text { transducer type }\end{array}$ & $\begin{array}{c}\text { Reference tank size, } \\
\text { in }^{3}\end{array}$ & $\begin{array}{c}\text { Update rate, } \\
\text { sample/s }\end{array}$ & $\begin{array}{l}\text { Resolution, } \\
\text { lbf } / \mathrm{ft}^{2}\end{array}$ & $\begin{array}{c}\text { Accuracy, } \\
\mathrm{lbf} / \mathrm{ft}^{2}\end{array}$ \\
\hline ISSM & Digital Absolute & --- & 17 & 0.0144 & 0.10 \\
\hline & Digital Absolute & --- & 17 & 0.0144 & 0.10 \\
\hline SSBD & Analog Differential & $252\left(p_{\text {diff }}\right.$ saturated $)$ & 400 & 0.0350 & 0.15 \\
\hline \multirow{2}{*}{ SSBE } & Digital Absolute & --- & 17 & 0.0144 & 0.10 \\
\hline & Analog Differential & $100\left(p_{\text {diff }}\right.$ in range $)$ & 977 & 0.0350 & 0.15 \\
\hline
\end{tabular}

For the ISSM test ${ }^{10}$ the digital absolute static pressure transducer measured the sonic boom signatures. Since these transducers only updated at 17 samples per second and a higher rate was desired, analog low-range differential pressure transducers were incorporated and were sampled at 400 samples per second for the SSBD flight phase. The sonic-boom-measuring noseboom, a modified National Advisory Committee for Aeronautics (NACA)-style noseboom, ${ }^{13}$ had additional static pressure ports located where the angle of attack and sideslip vanes would normally be. Figure 4 shows the sonic-boom-measuring noseboom and plumbing. These static ports are arranged in three pairs, each pair located \pm 37.5 deg laterally from the top side of the noseboom, which minimizes pressure variation during angle of attack changes. Each pair of ports is manifolded to a single tube of 0.18-in. inner diameter that runs $12 \mathrm{ft}$ back to the aircraft radome. Each of the forward and aft set of ports are connected to the front side of a separate analog differential pressure transducer with a range of \pm 1.0 psi. Dual pressure lines and transducers were used for redundancy. The center set of ports is manifolded to a 0.063 -in. inner diameter tube that runs $12 \mathrm{ft}$ back to a reference pressure tank. The back side of the differential transducers are manifolded to this tank. The tank absolute pressure was measured with another digital absolute pressure transducer, and tank temperature was also instrumented. This pneumatic arrangement allows pressure equalization across the sensitive differential transducers during relatively slow pressure changes, such as during climbs and descents, preventing transducer damage. During shock probing the reference tank pressure should not change rapidly, and the differential transducers sense the shock wave effects. The tank volume and pressure tube lengths and diameters must be chosen to balance these two functions.

Prior to the SSBD flight phase, simulations were run of the pressure dynamics to determine the appropriate tank and tubing dimensions. In order to achieve an acceptable response for both altitude changes and shock wave probing, a spare SR-71 nitrogen tank $\left(252 \mathrm{in}^{3}\right)$ was selected. Actual probing with this configuration during the SSBD flight phase showed that the tank was too large, and the differential transducer values were saturated for almost all the probings after diving to the test altitude. Since the SSBD flight phase for near-field probing lasted only five days, the pneumatic system could not be changed in time. The digital absolute static pressure measurement was used to determine the near-field probing for this flight phase, just as in the ISSM test.

The pneumatic simulation was adjusted using the SSBD flight phase data, and a new tank of 100 in $^{3}$ was fabricated. Seven grams of fiberglass house insulation was included in the smaller tank to prevent the pneumatic ringing that was seen in the larger tank data. A different data recorder was used which decreased transducer noise and also allowed 977-sample-per-second data. This configuration worked well for the SSBE flight phase. 


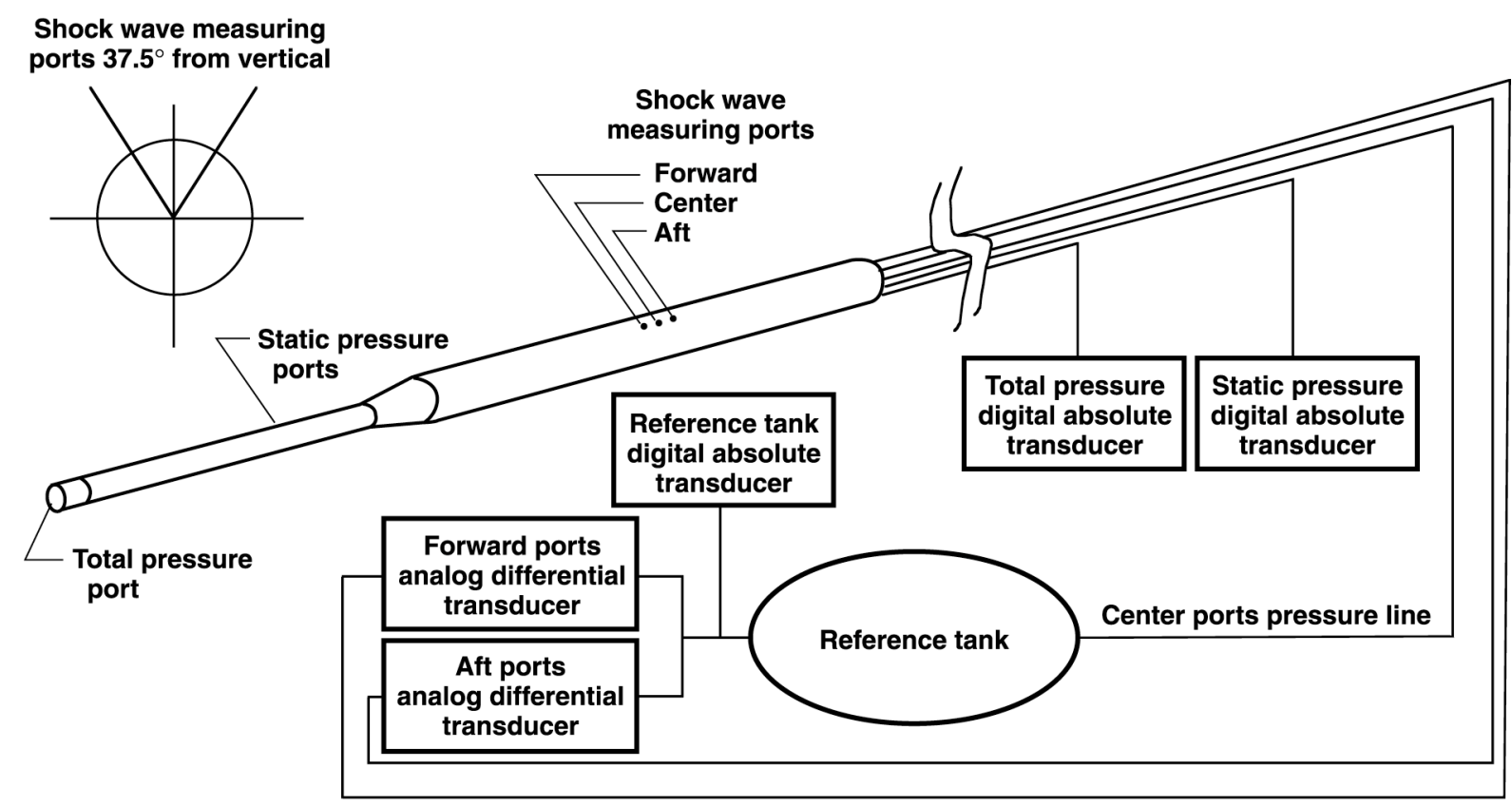

Figure 4. Sonic-boom-measuring noseboom and plumbing.

\section{The L-23 Sailplane Far-field Probing Aircraft}

The U.S. Air Force Super Blanik L-23 is a two-place sailplane manufactured by the Blanik company (Czechoslovakia), and is used by the U.S. Air Force Test Pilot School for student training and student-led flight test experiments. High-mounted wings with five degrees of forward sweep, shown in Fig. 3, make the sailplane wingtip a fine location for undisturbed microphone measurements.

The aircraft was outfitted with a Brüel and Kjær (Denmark) 4193 microphone on the port wingtip. This microphone had a bullet nose attachment and wind screen to minimize noise during flight. A Brüel and Kjær Nexus amplifier brought the microphone signal up to an acceptable voltage level for recording. This microphone and amplifier combination gave the highest signal-to-noise ratio of all the ground-level sensors. 8 A NASA Drydenconstructed Small Airborne Boom Event Recorder, ${ }^{14}$ SABER, recorded the microphone data on a spare channel. The normal pressure transducer of the SABER was plumbed to an existing spare static pressure port on the sailplane with a tube approximately 4 in. long. The SABER automatically records when a sonic boom is sensed on this transducer. Unfortunately, this 4-in. tube acted as an organ pipe and there was unacceptable noise superimposed on the shock wave. In spite of the noise on the pressure transducer, the SABER was still able to sense the sonic boom and so allow the microphone data to be recorded, which gave excellent results. The SABER contains a GPS receiver for time tagging of the sonic boom data. A Thales Navigation Z-Xtreme carrier-phase DGPS receiver was also installed on the aircraft for position and velocity information. A handheld GPS receiver with a moving map display was used for space positioning tasks, which greatly facilitated flying an exact ground track and being over the target on time.

\section{Atmospheric Measurements}

The last airborne measurement system used for this project is the GPS rawinsonde. This weather balloon system is comprised of a GPS receiver to determine ground reference position (for geometric height) and velocity (for wind speed-direction to determine lateral pressure gradients) along with sensors for measuring temperature and relative humidity, from which atmospheric pressure is derived. The GPS rawinsonde package is attached to a 100-ft line and tethered to a helium-filled latex balloon that lifts the instrumentation package at an approximate rate of 1,000 $\mathrm{ft} / \mathrm{min}$. The data for this program was recorded to 50,000 ft. The GPS rawinsondes were released from Edwards Air Force Base at 1200 coordinated universal time (UTC) (for comparison with worldwide launch time), prior to flight time (for go-no-go decisions), and as near to actual flight time as possible. 


\section{Maneuvers and Analysis}

For each aircraft, the flight maneuvers used and data analysis techniques will be described. The atmospheric analysis methods will also be discussed.

\section{A. The Shaped Sonic Boom Demonstration Aircraft}

The SSBD aircraft nominal test point condition was its design point, a pressure altitude of 32,000 ft and a Mach number of 1.4, but variations of Mach number and altitude were also flown. On every flight except three the aircraft was flown as steadily as possible over the ground microphone array. On three flights the SSBD aircraft performed a $0.25-G$ pushover maneuver to produce a focused sonic boom on the ground-level microphone array. ${ }^{15}$ A $2.0-G$ pullup maneuver was then executed to recover. During the SSBD flight phase, a constant altitude and constant airspeed turn was performed near the test altitude after overflying the microphone array in order to extract winds aloft from GPS velocity data.

1. GPS data fix

The GPS data are essential for both the Mach number calibration and for sonic boom data reduction. Typically, the raw data from the aircraft are processed with the raw data from the DGPS base station to provide position data to an accuracy generally better than $2 \mathrm{ft}$. Unfortunately, on six flights the raw DGPS data from the SSBD aircraft and the baseline F-5E aircraft was lost during data downloading. Fortunately, the real-time GPS data transmissions were received and recorded at the microphone array for most of the flights to allow ground personnel to see the progression of the flight. For flights when both raw and real-time data were recorded, the high-accuracy processed raw data were used to calibrate the lower accuracy real-time data. These calibrations were then applied to data for those flights when only real-time data was recorded to improve their accuracy.

\section{Pressure data fix}

The total and static pressure of the SSBD aircraft were measured using digital absolute pressure transducers updated at a maximum of 17 samples per second. The SSBD aircraft instrumentation system sampled these transducers at 100 samples per second. The total and static transducers did not update in unison. Without adjustment for the sample rates and asynchronous sampling, large computed jumps in Mach number occur. To avoid these jumps, 100-samples-per-second data for each transducer was processed removing adjacent repeated pressure values. The first instance of each new pressure value was used to interpolate the data to the full 100 samples per second. The interpolated values were then used to compute the airdata parameters such as Mach number and pressure altitude.

\section{Mach number calibration}

Data was gathered in order to calibrate the position error of the research pitot-static system. ${ }^{16}$ The carrier-phase DGPS data was combined with the atmospheric reference data to determine reference static pressure. Reference Mach number was computed from measured total pressure and reference static pressure, and indicated Mach number was computed from measurements of total and static pressure. The difference between reference and indicated Mach number is a function only of indicated Mach number during steady flight.

Figure 5 shows the Mach number correction as a function of the indicated Mach number of the SSBD aircraft. The trend is typical for position error on a noseboom installation, having zero error at Mach 0.0, a rapid rise in the high subsonic region, a steep reduction just faster than Mach 1.0, and a shallow slope in the supersonic region. For every flight when DGPS data was gathered, the Mach number correction was calculated, as shown by the red circles. A large hysteresis loop of greater than Mach 0.02 is seen in the supersonic region during the supersonic dive to the test condition and during a climb after the stabilized run was complete. The blue square symbols are those data considered stabilized, defined as the DGPS vertical speed less than $10 \mathrm{ft} / \mathrm{s}$, the bank angle less than $10 \mathrm{deg}$, and the DGPS root mean square error reported by the DGPS processing program less than $10 \mathrm{ft}$. This only occurred in the supersonic region, and there is much less scatter in the data when stabilized.

Figure 6 zooms in on the supersonic region, where a very consistent flight-to-flight Mach number correction is seen. The Mach number calibration is shown as a black line, and 68 percent of the stabilized data (blue squares) is within Mach 0.00087 of this line, which translates to an altitude variation of $\pm 22 \mathrm{ft}$. This percentage would correspond to one standard deviation if the data had a normal distribution, but the extremes of the data are not random, and are probably because of variability in the atmosphere, as well as the pressure and DGPS sensors. This very small variability using GPS rawinsondes and DGPS data is almost six times less than calibrations made with conventional non-GPS rawinsondes and ground-based radar data. ${ }^{17}$ 


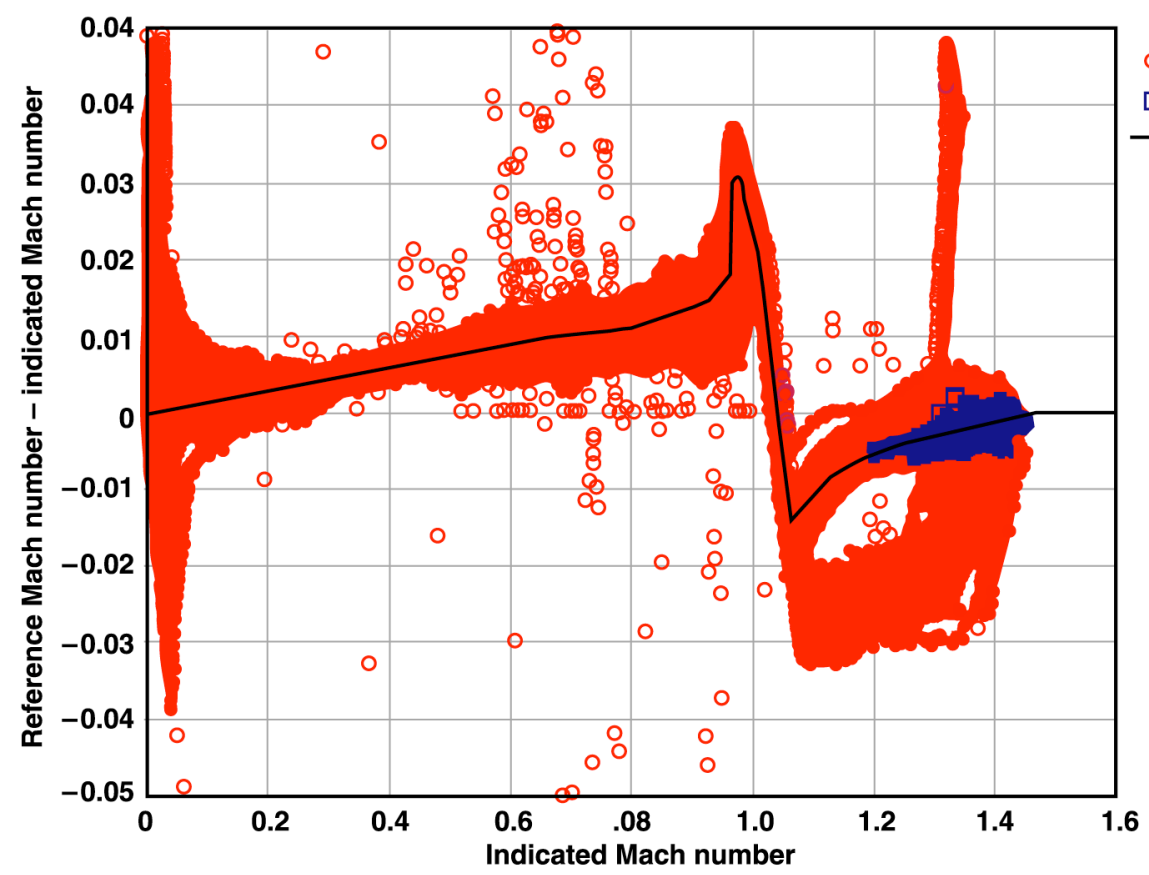

- All data fits $5-14,16-33$

$\square$ Stable data fits $5-14,16-33$

Calibration

Figure 5. Mach correction for SSBD aircraft.

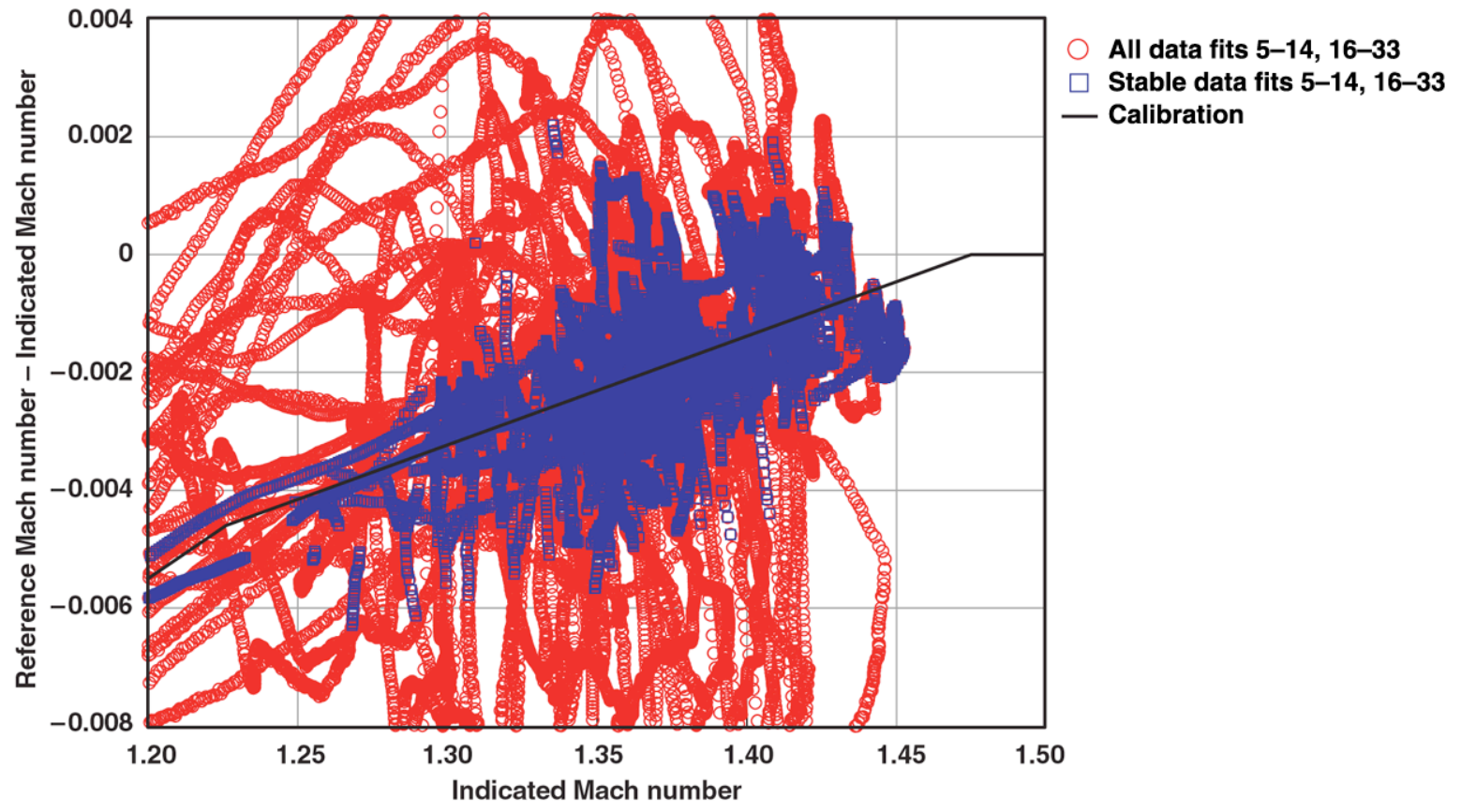

Figure 6. Mach correction for SSBD aircraft, supersonic.

Because of the large hysteresis loop seen in Fig. 5, this Mach calibration alone would not be sufficient accuracy for the dynamic sonic boom focus maneuver, ${ }^{15}$ which included a pushover to $0.25 \mathrm{G}$ and pullup to $2.0 \mathrm{G}$. To assess the magnitude of the pneumatic lag on the research airdata system of the SSBD aircraft, a ground test was performed with pressure step functions applied at the noseboom. The pressure at the static and total pressure ports were independently changed from ambient, and then allowed to vent to atmospheric pressure as rapidly as possible. A SABER was used to measure the pressure at the noseboom port, and the instrumentation system of the SSBD 
aircraft recorded the lagged pressure. Unfortunately, it was discovered after completion of the test that the fixture used to apply pressures to the noseboom had a leak between the total and static pressure lines, and the instrumentation system of the SSBD aircraft had been dismantled before the test could be repeated. These data can still be used, however, to define an outer bound to the pneumatic lag. Analysis of these data is ongoing at this time. For flight conditions of the SSBD aircraft during the sonic boom focus maneuver, DGPS data and atmospheric reference pressure data are used without pneumatic data from the SSBD aircraft. Because the baseline F-5E aircraft had no recording of airdata sensors, its DGPS velocity with atmospheric pressure, winds, and temperature were used to compute the airdata state of the baseline F-5E aircraft.

\section{B. The F-15B Aircraft}

The F-15B probing aircraft flew in close formation with the SSBD aircraft from takeoff until the completion of probing maneuvers for each flight. If the two aircraft had a large separation, valuable test time would be wasted rejoining. As the SSBD aircraft dove and accelerated to the desired test point, the F-15B aircraft moved from a close formation at the side of the SSBD aircraft to below and behind the SSBD aircraft to prepare for supersonic probing. When the pilot of the SSBD aircraft declared that he was on condition and stable, the pilot of the F-15B aircraft advanced the throttles and slowly moved forward through the SSBD aircraft shock waves from back to front. The pilot of the F-15B aircraft kept his eyes mostly on the SSBD aircraft, attempting to remain in the proper orientation. The back-seater of the F-15B aircraft assisted by monitoring the separation between both aircraft and providing the pilot of the F-15B aircraft with situational awareness information such as Mach number and altitude deviations, positioning within the test airspace, and aircraft fuel state. Engineers in the control room monitored relative aircraft position and the pressure data from the noseboom of the F-15B aircraft, and when the pressure data showed that the bow shock had been measured, a "Back Up" call was made to the pilot of the F-15B aircraft. The throttles on the F15B aircraft were then retarded slightly, and a front-to-back probing was made. Figure 7 shows a schematic of nearfield probing. At no time was the nose of the F-15B aircraft forward of the tail of the SSBD aircraft during supersonic probing, satisfying a mission rule. Probing flights were performed on the SSBD aircraft flight numbers 8 and 12 in the SSBD flight phase, and flight numbers 30 through 33 in the SSBE flight phase. For each of these flights, the probings were numbered sequentially, for example, the sixth probing of flight 30 is denoted as pressure signature 30-6, as shown in Fig. 7. This signature 30-6 was probed front to back, performed after the back-to-front signature 30-5. This naming convention will be used throughout this paper.

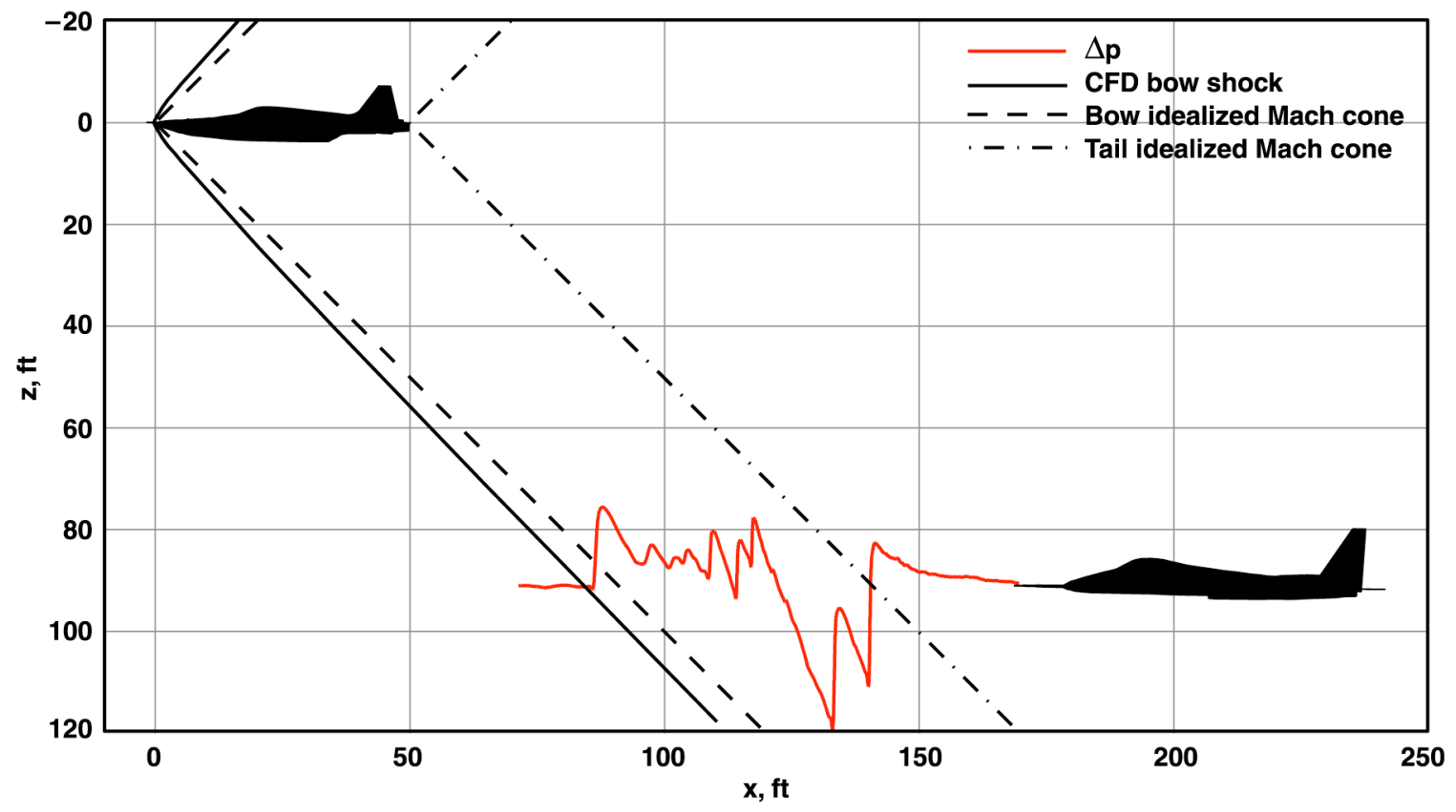

Figure 7. Schematic of near-field probing for pressure signature 30-6. Idealized bow and tail Mach 1.414 cones for $\mathbf{y}=\mathbf{0}$. 
Near-field probing was easily accomplished for the aircraft separations that were flown. The probing aircraft needed an inertial reference to assist in maintaining a level flightpath while flying through the shock waves. For this reference the pilot used the inertial navigation system-derived velocity vector symbol on the head-up display (HUD) of the F-15B aircraft. The pilot kept this symbol on the horizon to remain level while probing, as the altimeter readings had large excursions because of the SSBD aircraft shock waves. As the aircraft separation increased, the pilot of the F-15B aircraft needed more assistance to ensure that the F-15B aircraft had moved far enough forward to capture all of the shock data. Also, real-time monitoring in the control room was useful to ensure an acceptable rate of shock penetration. A fly-to command display in the HUD would have improved the precision of the trajectory. This display should include vertical and lateral offset information and rate of penetration information. Such a display was available in the F-15B aircraft control room, but because of communication latencies this could not be used in real time during the probing. The ground controller would use this display to advise the pilot of future relative positioning corrections. The SSBD project schedule did not allow incorporation of this display in the F-15B aircraft.

There are two components needed to define the near-field pressure signatures: the geometric separation of the aircraft, and the pressure variations from ambient because of the shock waves. The techniques to determine each are discussed below.

\section{Geometric Corrections to Shaped Sonic Boom Demonstration Aircraft Stability Axes}

First, a stability axes system with origin at the nose of the SSBD aircraft, not including the short noseboom, is defined. The $x$ axis points rearward (parallel to the airmass relative airspeed vector), the $y$ axis points out of the left wing of the SSBD aircraft, and the $z$ axis is perpendicular to $x$ and $y$, mostly downward. Sideslip is assumed to be zero throughout. A combination of measurements and coordinate transformations is required to determine the position of the F-15B aircraft pressure port in this axes system.

The raw GPS data from each aircraft were differentially corrected with the fixed GPS base station data to determine the absolute position of each aircraft. When processing these DGPS data, various settings of the processing software [Precise Differential GPS Navigation and Surveying (PNAV) v2.5.07 by Ashtech] were tried. The GPS carrier wavelength is about $19 \mathrm{~cm}$. Carrier-phase differential GPS data accurately measures the fractional wavelength remainder between each GPS satellite and the GPS receiver, and the post-mission software tries to determine the number of integer wavelengths, which is referred to as integer ambiguity resolution. The greatest accuracy data is achieved if the integer ambiguity is fixed before the flight begins, and then wavelengths are added or subtracted as time goes on. This works well if the GPS receiver never loses the signal from the satellites, but for these flights individual satellite signals were lost on occasion, requiring the software to attempt to resolve the integer ambiguity on the fly, increasing error. The software can also be set to allow the integer ambiguities to float, which should result in somewhat lower position accuracy but without jumps occurring in the data when individual satellite signals are lost. Alternate software was also investigated to determine relative position, which computes relative position without the use of base station data. The PNAV software with integer ambiguities allowed to float was used for the airdata calibration, far-field, and ground signature data. The PNAV software with fixed integer ambiguities was used for the near-field probing data, as it gave superior results when comparing the flight data to the CFD data.

The DGPS receiver of each aircraft measures the inertial position of its own GPS antenna. The DGPS position of the SSBD aircraft was translated to the nose of the aircraft, and the DGPS position of the F-15B aircraft was translated to the pressure port that measures the shock waves. Since the Euler angles of the F-15B aircraft were not measured, and the Euler angle measurements of the SSBD aircraft did not have sufficient accuracy for this computation, an assumed angle of attack plus the DGPS-derived flightpath angle and atmospheric reference winds aloft were used to estimate pitch angle. The assumed angle of attack of the SSBD aircraft was $1.75 \mathrm{deg}$, and $1.0 \mathrm{deg}$ was assumed for the F-15B aircraft. The DGPS-derived flightpath heading and atmospheric reference winds aloft were used for yaw angle, and zero roll angle was assumed.

After translation, the new World Geodetic Survey of 1984 (WGS84) system geodetic latitude, longitude, and

ellipsoid altitude, $\lambda, \theta$, and $Z$ respectively, for each aircraft were transformed into earth-centered Cartesian coordinates $x c, y c$, and $z c$ by Eq. (1). ${ }^{18}$ 


$$
\begin{aligned}
& x c=\left(\frac{a}{\sqrt{1-e c^{2} \sin ^{2} \lambda}}+Z\right) \cos \lambda \cos \theta \\
& y c=\left(\frac{a}{\sqrt{1-e c^{2} \sin ^{2} \lambda}}+Z\right) \cos \lambda \sin \theta \\
& z c=\left(\frac{a\left(1-e c^{2}\right)}{\sqrt{1-e c^{2} \sin ^{2} \lambda}}+Z\right) \sin \lambda
\end{aligned}
$$

where $a$ is the semimajor axis of the Earth ellipsoid, and $e c$ is the eccentricity of the Earth ellipsoid.

The GPS receivers report data on the even half-second increment accurate within a few nanoseconds. The DGPS data from the two aircraft were synchronized, and using Eq. (2) were differenced to give separation components north, east, and down from the nose of the SSBD aircraft to the pressure port of the F-15B aircraft.

$$
\left[\begin{array}{l}
n \\
e \\
d
\end{array}\right]=\left[\begin{array}{ccc}
-\sin \lambda \cos \theta & -\sin \lambda \sin \theta & \cos \lambda \\
-\sin \theta & \cos \theta & 0 \\
-\cos \lambda \cos \theta & -\cos \lambda \sin \theta & -\sin \lambda
\end{array}\right]\left[\begin{array}{l}
x c_{F-15 B}-x c_{S S B D} \\
y c_{F-15 B}-y c_{S S B D} \\
z c_{F-15 B}-z c_{S S B D}
\end{array}\right]
$$

The inertial GPS velocities are reported in north, east, and down components. The atmospheric reference data was then interpolated to give north and east wind components for every time point of the SSBD aircraft, and combined with the GPS velocities to give airmass relative velocity components. Since the atmospheric sensors do not measure vertical wind components, the vertical winds were assumed to be zero. Airmass relative flightpath angle, $\gamma$, and flightpath heading, $\psi$, were then determined from the airmass relative velocity components using Eqs. (3) and (4):

$$
\begin{gathered}
\gamma=\tan ^{-1}\left(\frac{-v_{d}}{\sqrt{\left(v_{n}+w_{n}\right)^{2}+\left(v_{e}+w_{e}\right)^{2}}}\right) \\
\psi=\tan ^{-1}\left(\frac{v_{e}+w_{e}}{v_{n}+w_{n}}\right)
\end{gathered}
$$

These angles are then used to rotate the north, east, and down separation components, $n, e$, and $d$ into the SSBD aircraft stability axes, $x, y$, and $z$ separation components using Eq. (5).

$$
\begin{aligned}
& {\left[\begin{array}{l}
x \\
y \\
z
\end{array}\right]=\left[\begin{array}{ccc}
\cos (-\gamma) & 0 & -\sin (-\gamma) \\
0 & 1 & 0 \\
\sin (-\gamma) & 0 & \cos (-\gamma)
\end{array}\right]\left[\begin{array}{ccc}
\cos (\psi+180) & \sin (\psi+180) & 0 \\
-\sin (\psi+180) & \cos (\psi+180) & 0 \\
0 & 0 & 1
\end{array}\right]\left[\begin{array}{l}
n \\
e \\
d
\end{array}\right] } \\
&= {\left[\begin{array}{ccc}
-\cos \gamma \cos \psi & -\cos \gamma \sin \psi & \sin \gamma \\
\sin \psi & -\cos \psi & 0 \\
\sin \gamma \cos \psi & \sin \gamma \sin \psi & \cos \gamma
\end{array}\right]\left[\begin{array}{l}
n \\
e \\
d
\end{array}\right] }
\end{aligned}
$$


The azimuthal angle, $\phi$, is defined as the offset angle from the vertical plane of the SSBD aircraft and is given by Eq. (6).

$$
\phi=\tan ^{-1}\left(\frac{y}{z}\right)
$$

Figure 7 shows the bow shock location in $x$ and $z$ for the case of Mach 1.414. This location was determined using the GCNSfv ${ }^{11}$ CFD code. Also shown are the idealized Mach cones emanating from the nose and tail of the SSBD aircraft, which for this Mach number make nearly 45-deg lines on the vertical plane. The idealized Mach cone would be formed by disturbances traveling at the freestream speed of sound, and is only valid for an infinitesimally weak shock wave. Since the bow shock has significant strength, its propagation speed is faster than the freestream speed of sound, ${ }^{19}$ and so it travels forward of the bow idealized Mach cone. We would like to present the near-field pressures as a function of distance back from the bow shock, especially when there are variations in $y$ and $z$. Since the bow shock location is difficult to compute, the pressures will be presented as a function of the distance behind the idealized Mach cone, $x_{\text {cone }}$, which is readily computed using Eq. (7).

$$
x_{\text {cone }}=x-\sqrt{\left(y^{2}+z^{2}\right)\left(\mathrm{M}^{2}-1\right)}
$$

In Fig. 7 at $z=91 \mathrm{ft}$, the bow shock is at about $x=86 \mathrm{ft}$ and the idealized Mach cone is at $91 \mathrm{ft}$. Therefore, the bow shock will be located at about $x_{\text {cone }}=-5 \mathrm{ft}$. Equations (5)-(7) yield the time history of the relative separation during the probing, and these are combined with the overpressure data, which are described below.

\section{Pressure Corrections}

In order to eliminate noise from the instrumentation system on the F-15B aircraft, the reference tank absolute pressure and the analog differential pressures were forward-backward filtered using a third-order lowpass Butterworth digital filter, with cutoff frequencies of 0.061 and $12.5 \mathrm{~Hz}$ respectively.

Overpressure, $\Delta p$, caused by the shock waves of the SSBD aircraft, is desired, which should have a value of zero before the bow shock and also far behind the tail shock. As the F-15B aircraft probes through the SSBD aircraft shock waves, there can be altitude variations by the F-15B aircraft, which will affect the pressure readings. The indicated pressure altitude of the F-15B aircraft is greatly affected by the shock waves from the SSBD aircraft, so variations in DGPS-determined geometric altitude are used to adjust the pressure readings.

$$
\begin{gathered}
\Delta p=p_{s_{i}}-f\left[Z-\left(Z_{0}-f^{-1}\left\{p_{s_{i_{0}}}\right\}\right)\right] \\
\Delta p=p_{\text {diff }}+p_{\text {tank }}-f\left[Z-\left(Z_{0}-f^{-1}\left\{p_{\text {diffo }}+p_{\text {tank }}\right\}\right)\right]
\end{gathered}
$$

where the subscript 0 denotes a single point where the overpressure can reasonably be assumed to be zero, generally ahead of the bow shock, but sometimes well aft of the tail shock. The function $f$ uses the U.S. Standard Atmosphere to convert pressure altitude to pressure, and the function $f^{-1}$ converts pressure to pressure altitude. ${ }^{18,}{ }^{20}$ Equation (8) is used when the static pressure port is used to measure the shock waves (ISSM and SSBD flight phases), and Eq. (9) is used with the differential pressure transducer and lag tank (SSBE flight phase).

\section{The L-23 Sailplane}

The Super Blanik L-23 sailplane was towed into position overhead the ground array at a pressure altitude of $10,000 \mathrm{ft}$ or $8,000 \mathrm{ft}$ just prior to the SSBD aircraft overflight. The researchers desired that the sailplane be on the same ground track as the SSBD aircraft. Initially they were instructed to be directly overhead the center point of the ground array when the boom occurred, but that was soon changed to be exactly "up boom" of the center point so that ideally the boom measured by the ground array literally traveled past the sailplane. 
The onboard instrumentation of the sailplane was set to trigger automatically from a sudden static rise. A shakedown flight revealed that a steep turn could generate enough sideslip to trigger the static pressure sensor. This was problematic because once triggered, the recorder was effectively deaf for $10 \mathrm{~s}$ while it downloaded the data to nonvolatile memory. To ensure a quiet platform and decrease the chances of an accidental trigger, the aircrew ensured that all the sailplane vents were closed and that they were flying wings-level at a slow cruise speed (but not so slow as to cause stall buffet), about $45 \mathrm{kn}$.

Approximately $16 \mathrm{~s}$ after the SSBD aircraft flew overhead, the sonic boom was heard in the cockpit and recorded by the SABER system. About $6 \mathrm{~s}$ later a second boom that had reflected off the ground came back to the sailplane and was recorded.

\section{Geometric Corrections to Stationary Observer}

Because of the large propagation distances to the far-field location, the signatures measured by the sailplane are more like those of ground recordings than those measured by the F-15B near-field probing aircraft, and have the added benefit of having less turbulence effects than ground recordings. Therefore, the sailplane measurements were transformed into what would be measured by a stationary observer at the location and altitude of the sailplane. Because the sailplane was generally flying in the same direction as the supersonic aircraft during the measurements, the measurements were stretched in time as compared to the ground signatures. The amount of stretching is a function of the ratio of the inertial velocities of the aircraft in the direction of the supersonic aircraft. The GPS receiver of the SABER determined the true time the bow shock is measured, $t_{b o w}$, and the stationary observer time, $t_{s o}$, is given by Eq. (10):

$$
t_{s o}=\left(t_{L 23}-t_{b o w}\right)\left(1-\frac{v_{n}^{*} v_{n s}+v_{e}^{*} v_{e s}+v_{d}^{*} v_{d s}}{v_{n}^{* 2}+v_{e}^{* 2}+v_{d}^{* 2}}\right)+t_{b o w}
$$

where $t_{L 23}$ is the measured time history on the sailplane; $v_{n s}, v_{e s}$, and $v_{d s}$ are the DGPS velocity components in the north, east and down directions of the sailplane; and $v_{n}^{*}, v_{e}^{*}$, and $v_{d}^{*}$ are the DGPS velocity components at the time $t_{\text {bow }}-\Delta t_{\text {prop }}$ of the supersonic aircraft. The parameter $\Delta t_{\text {prop }}$ is the shock wave propagation time from the supersonic aircraft to the sailplane as determined by a sonic boom propagation code. The inertial velocity vectors are determined by carrier-phase DGPS data on both aircraft. PCBoom $4^{21}$ was used in this analysis to determine $\Delta t_{\text {prop }}$ for each flight, about $38 \mathrm{~s}$. As the time is compressed from the sailplane to the stationary observer, the effective sample rate of the recording increases. Altitude changes of the sailplane were neglected when running PCBoom4, but are negligible as the vertical speed was typically less than $5 \mathrm{ft} / \mathrm{s}$ and the duration of the signatures were about $80 \mathrm{~ms}$.

\section{Pressure Corrections}

For each flight of the sailplane, a Brüel and Kjær pistonphone was used on the ground for calibration data of the microphone. The bullet nose and windscreen were removed for calibration, and reattached before flight. At times there were slight offsets in the microphone measurements before the sonic boom signatures were recorded, and these were zeroed out in the final pressure data. Because these are free-air measurements, there is not the usual 1.9 reflection factor that is present in ground-measured signatures.

\section{Atmospheric Analysis}

For each of the flights, weather map reanalysis was performed to create height, temperature, and wind profiles for the mandatory reporting levels. This analysis was then compared to the Edwards balloon profiles for consistency, allowing the rawinsonde data to be checked for possible bad data points (e.g. faulty temperature readings) that may throw off the derived pressure and height calculations. A few individual rawinsondes had altitude errors in excess of $300 \mathrm{ft}$, but these errors were corrected with recomputation with its raw data. Further comparisons were made with the Edwards balloons and nearby rawinsonde launch sites including Vandenberg Air Force Base, California, Mercury Desert Rock Airport, Nevada, and Miramar Marine Corps Air Station, California. If available, off-hour launches at China Lake Naval Weapons Station, San Nicholas Island Naval Outlying Field, and Point Mugu Naval Air Station (all in California) were used in the analysis.

The final step performed was adjusting the balloon data both spatially and temporally to coincide with the times and locations of the flight data points. This adjustment must take into account the overall general synoptic activity (warm-cold air advection, height rises-falls, etc.), the natural semidiurnal "swell" caused by surface heating and atmospheric tide effects, and for the more remote Harper Lake deployment ${ }^{8}$ during the SSBD flight phase, the 
spatial difference between the balloon launch site and the flight track. The adjustments included adjusting the upper-level temperatures to flight time-location adjustments, reinitializing the surface data for flight time, and finally recalculating the pressures-heights using the new initialization and temperature profile.

\section{Sonic Boom Flight Results}

After applying the various corrections, calibrations, and adjustments to the raw data as described above, the near- and far-field probing signatures of the SSBD aircraft can now be presented. The SSBD aircraft flight conditions were used as inputs to the CFD program, ${ }^{11}$ and also to the sonic boom propagation code. ${ }^{21}$ The near-field probing flight data can be used to validate the CFD codes. Since the far-field probing data is transformed into what would be observed by a stationary observer, the bulk of these data are presented with the ground data in Ref. 8 . The final atmospheric reference data is used by sonic boom propagation codes, and also with the DGPS data of the baseline F-5E aircraft, to determine its flight conditions.

\section{A. The F-15B Aircraft Near-field Probing Flight Data}

Figure 8 shows 68 near-field probings that were made over six flights at distances of 60 to $720 \mathrm{ft}$ from the SSBD aircraft. The majority of these were made directly below the SSBD aircraft at approximately $100 \mathrm{ft}$ separation, but some were also performed at significant azimuthal angles to the side, $\phi$, as shown in the inset plot of Fig. 8. The details of the near-field signature are best defined with the lowest differential speed between the SSBD and F-15B aircraft, but the straightest probing path occurs with the highest differential speed. The pressure details are of the most interest, and a technique was developed to account for variability in the probing path, so the slowest overtake passes were of the most value.

Figure 9 shows one of the more detailed signatures, with a photo of the SSBD aircraft superimposed on the graph scaled to match the bow and tail shock waves. The overpressure is plotted as a function of $x_{\text {cone }}$ given in Eq. (7). Note that the bow shock is not located at $x_{\text {cone }}=0$ because the bow shock speed is greater than the freestream speed of sound. ${ }^{19}$ The inset plot in the lower left shows the trajectory of the F-15B aircraft in the SSBD aircraft stability axes and the overpressure, along with Mach lines radiating from the SSBD aircraft nose and tail. The arrow denotes the probing direction. The inset plot in the lower right shows a rear view of the probing, in this case under the SSBD aircraft flightpath. The semicircles have an increment of $50 \mathrm{ft}$.

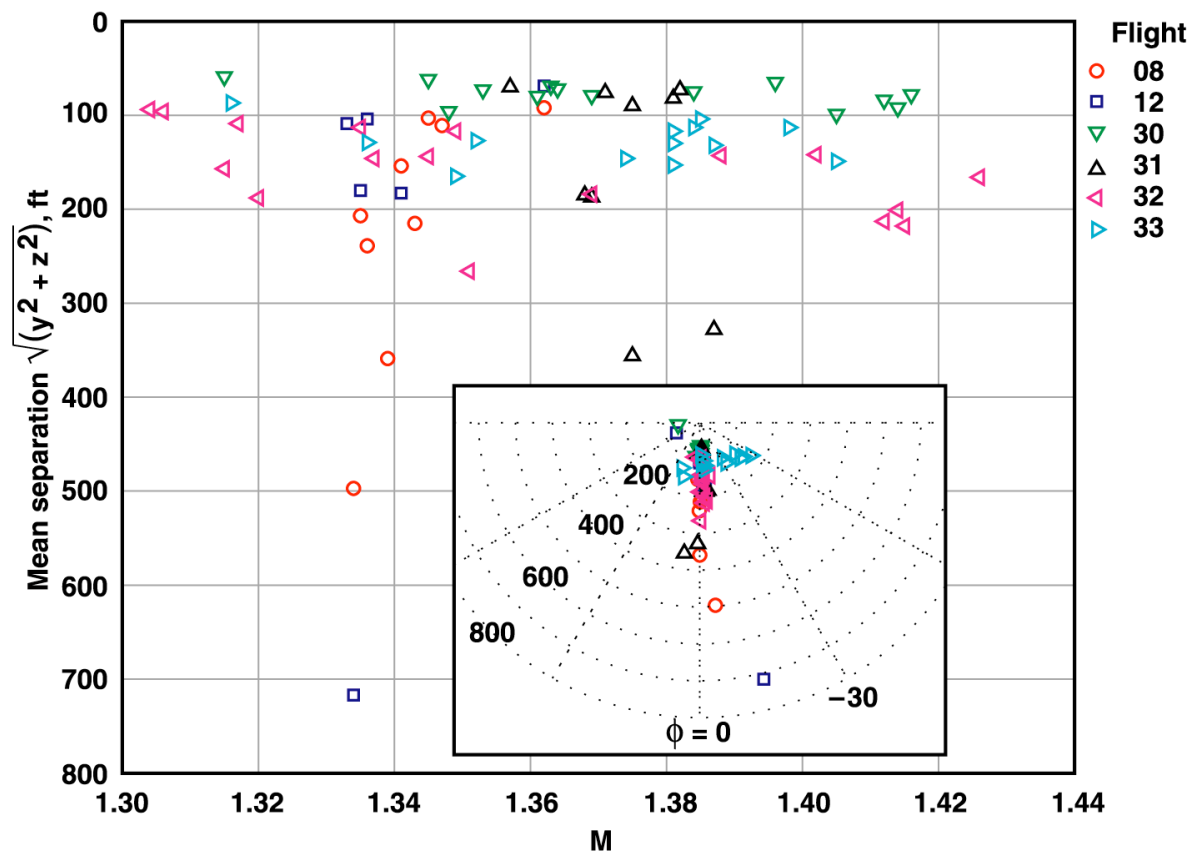

Figure 8. Near-field probing separation distances, Mach numbers, and azimuthal angles. 


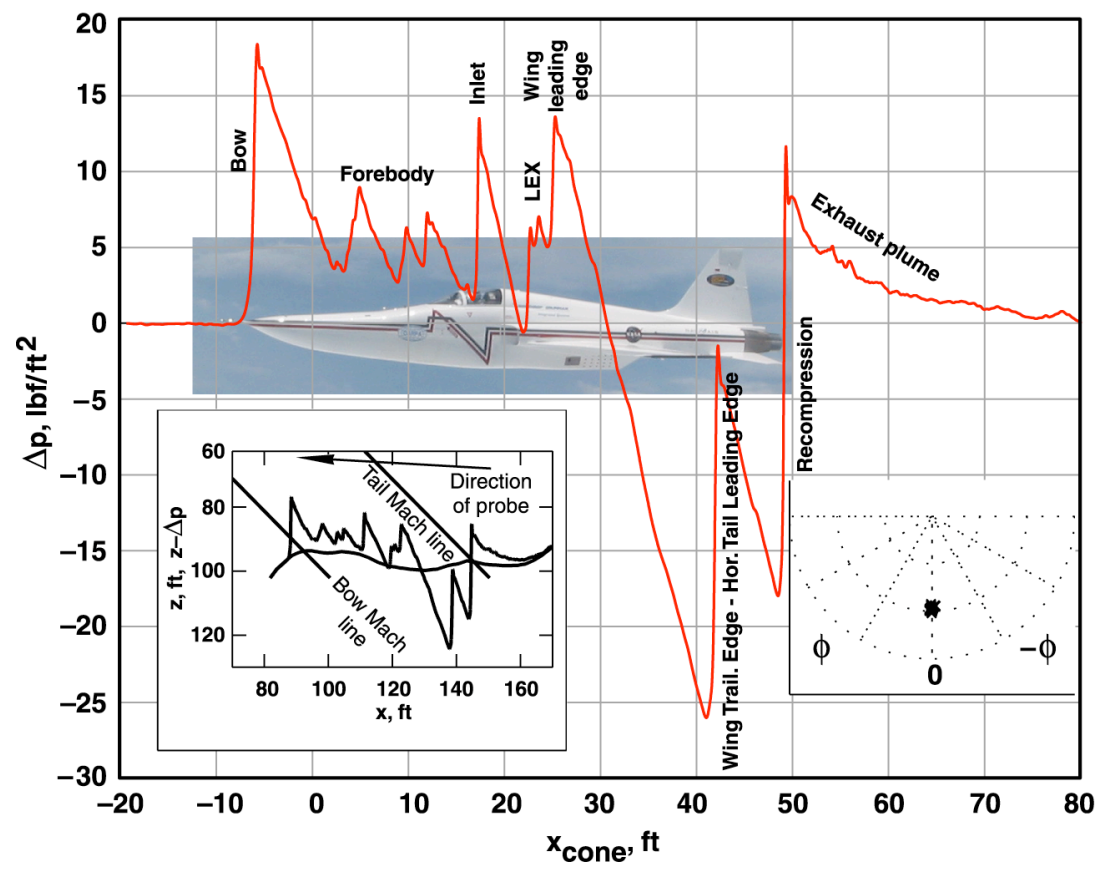

Figure 9. Near-field probing flight data with SSBD aircraft photograph, signature 30-5.

Various features of the signature of the SSBD aircraft can be seen in Fig. 9. There is a very strong bow shock, which prevents the following shocks from moving forward. There are three small shocks from the forebody. These shocks were not intended in the design, but are a consequence of preserving the pilot's view during landing. At an $x_{\text {cone }}=17 \mathrm{ft}$ there is the engine inlet shock. Behind this are two little shocks near $x_{\text {cone }}=23 \mathrm{ft}$, probably from the wing leading edge extensions (LEX), followed by the wing leading edge shock. A strong expansion is then encountered, followed by a shock from the wing trailing edge and horizontal tail leading edge. A final recompression shock wave at the back of the aircraft is visible, followed by an asymptotic expansion caused by the exhaust plume.

Flight conditions for pressure signatures that will be compared to CFD results are shown in Table 2. The mean Mach number and mean pressure altitude are determined from the total and static pressure on the SSBD aircraft along with the Mach number calibration of the SSBD aircraft. Total aircraft weight is determined from aircraft zero fuel weight and pilot radio calls of fuel quantity. The lift coefficient is calculated from total aircraft weight, wing area, mean Mach number, and mean pressure altitude, assuming 1- $G$ flight. Angle of attack is determined by iterating GCNSfv ${ }^{11}$ CFD solutions to match the calculated lift coefficient. For all CFD solutions the SSBD aircraft tail deflection was set for trim at the design flight condition of Mach 1.4 and 32,000 ft pressure altitude. The corrected air mass flow through the inlets was determined with an engine deck adjusted for the ISSM flight data at each flight condition. ${ }^{10}$

Table 2. Shaped Sonic Boom Demonstration aircraft flight conditions.

\begin{tabular}{lcccccc}
\hline \hline Flight-Signature & $8-2$ & $30-6$ & $30-9$ & $30-11$ & $31-2$ & $32-17$ \\
\hline Mean Mach number & 1.347 & 1.414 & 1.348 & 1.361 & 1.381 & 1.345 \\
Mean pressure altitude, ft & 31,376 & 32,140 & 32,375 & 32,062 & 31,787 & 32,520 \\
Total aircraft weight, lb & 13,262 & 13,894 & 13,083 & 12,924 & 14,050 & 12,695 \\
Lift coefficient & 0.0950 & 0.0936 & 0.0980 & 0.0936 & 0.0976 & 0.0962 \\
Angle of attack, deg & 1.790 & 1.922 & 1.834 & 1.802 & 1.892 & 1.802 \\
Corrected air mass flow, lbm/s & 57.3 & 58.0 & 58.7 & 58.5 & 59.1 & 59.3 \\
Figure & 10 & 11 & 12 & 13 & 14 & 15 \\
\hline \hline
\end{tabular}

Figures 10-15 show flight data for these six signatures. All of these figures show generally the same features. Forward probing is shown in Figs. 10 and 12-14, while backwards probing is shown in Figs. 11 and 15. For slow overtake speeds the data is more sharp, and forward probing was generally slower than backward probing. The data in Fig. 10 was performed in the SSBD flight phase, and so has the slower-rate pressure transducers. 


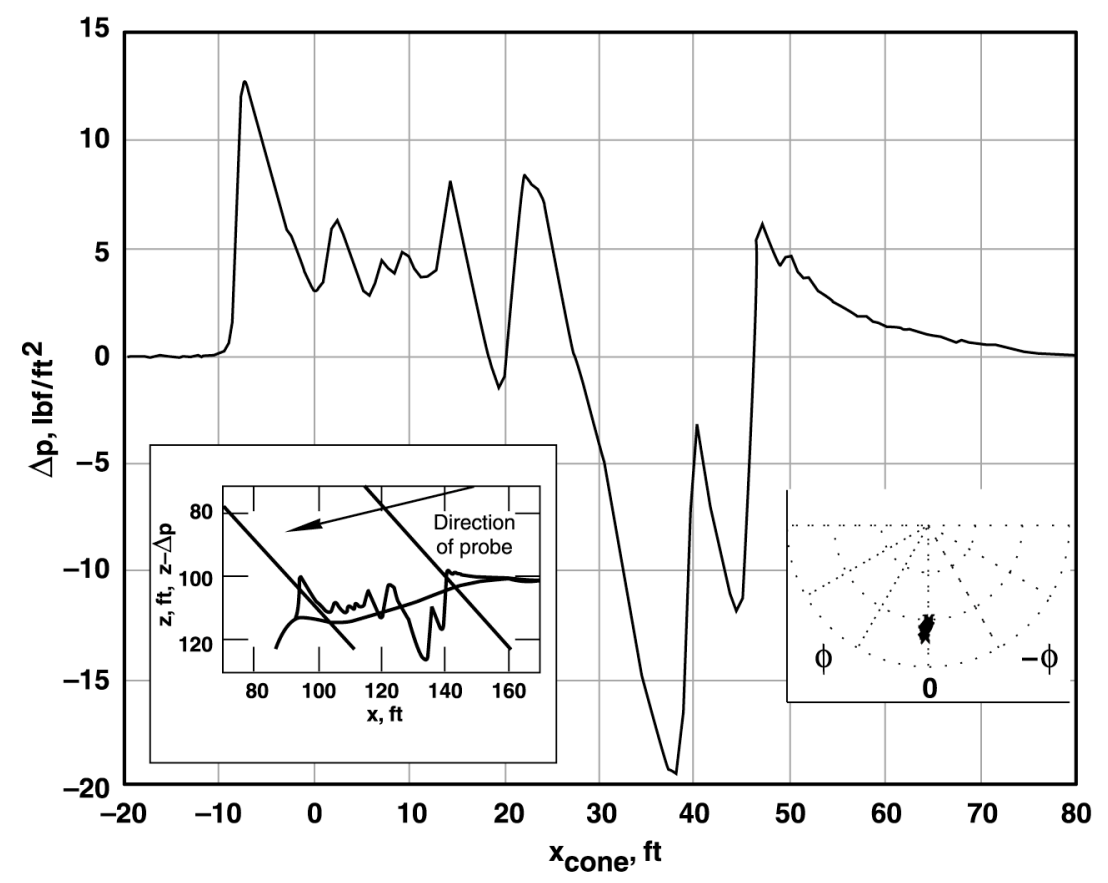

Figure 10. Near-field probing flight data, signature 8-2.

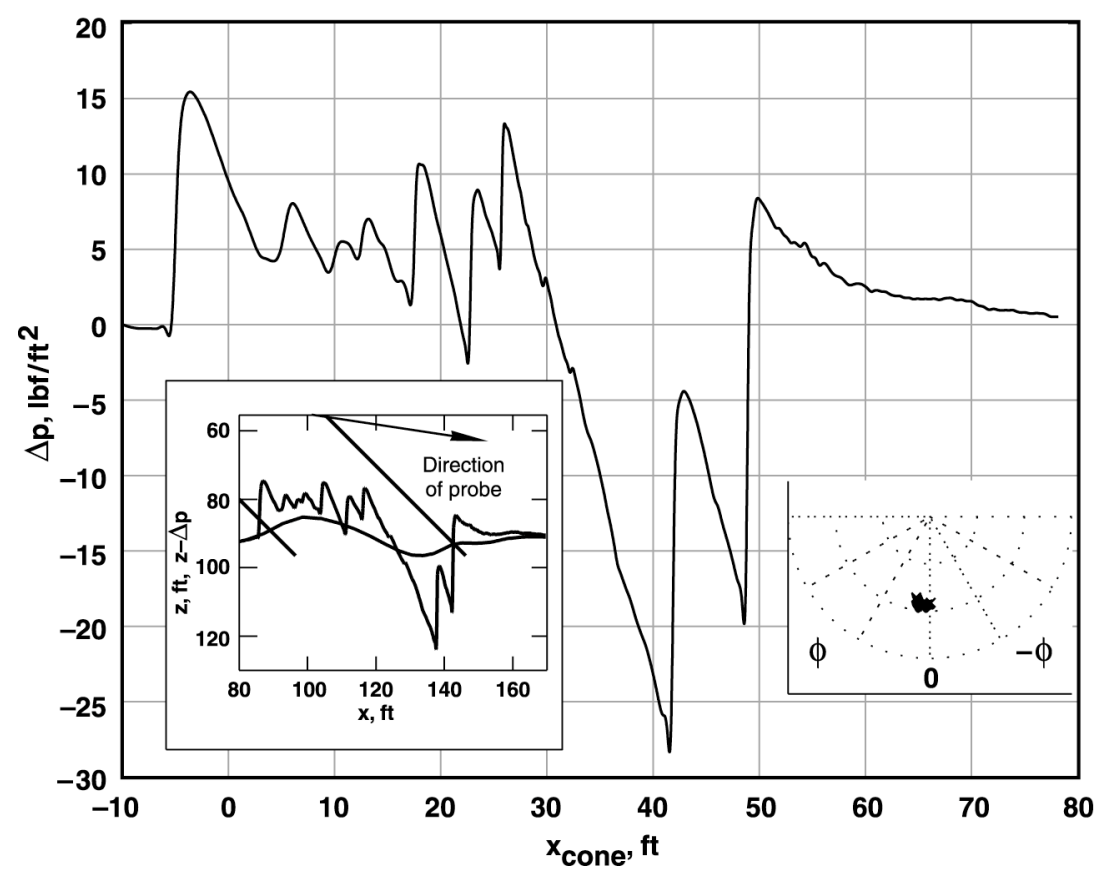

Figure 11. Near-field probing flight data, signature 30-6. 


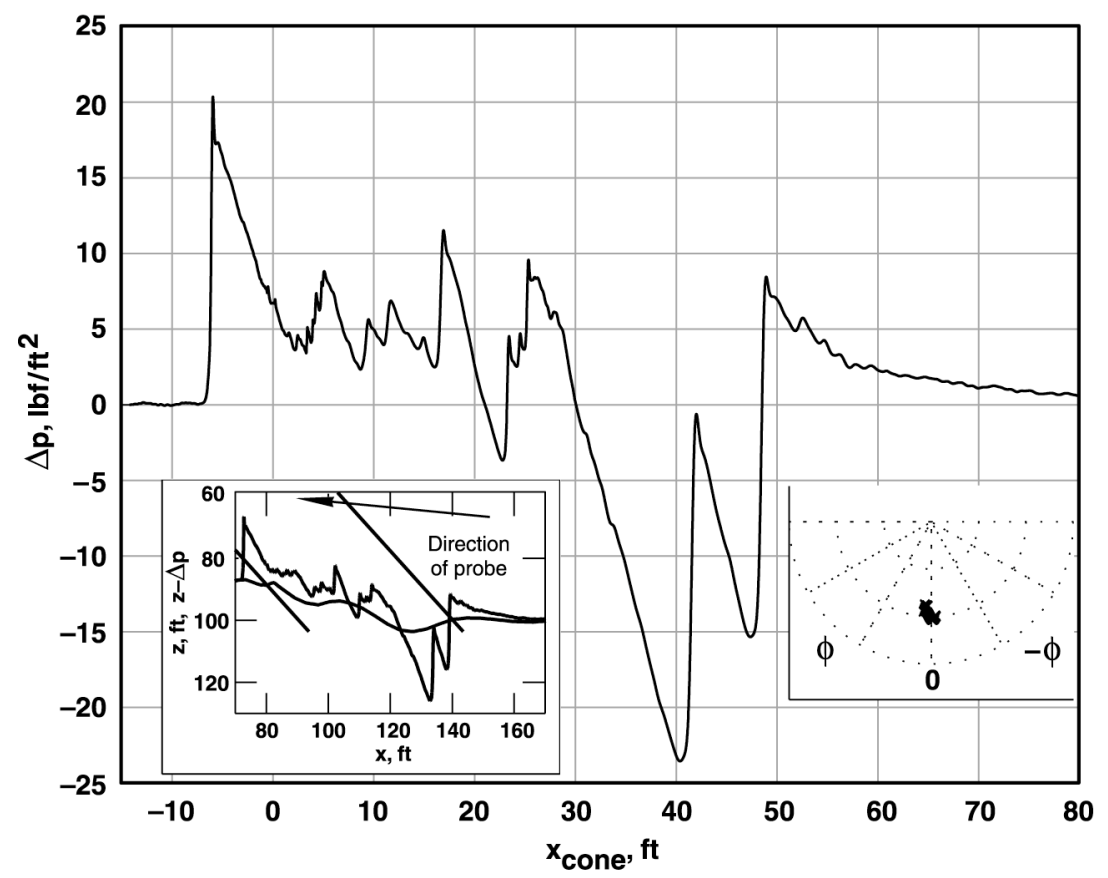

Figure 12. Near-field probing flight data, signature 30-9.

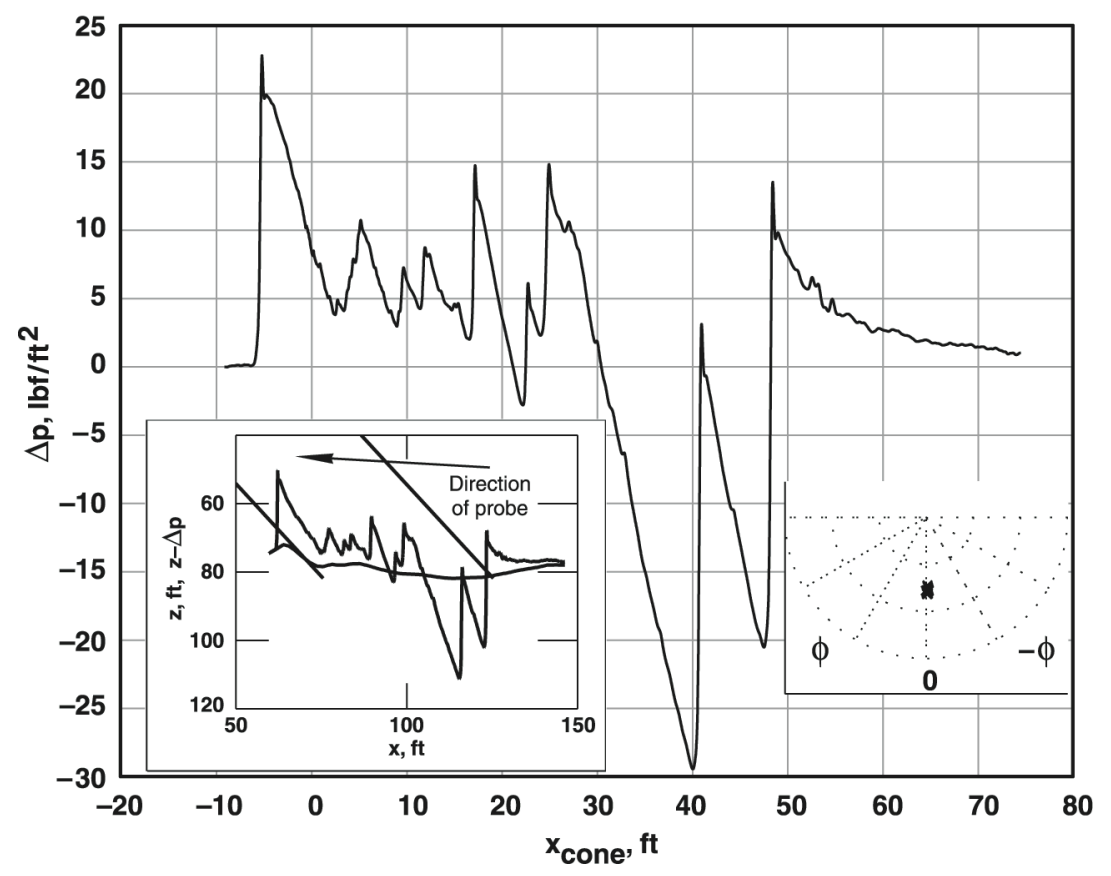

Figure 13. Near-field probing flight data, signature 30-11. 


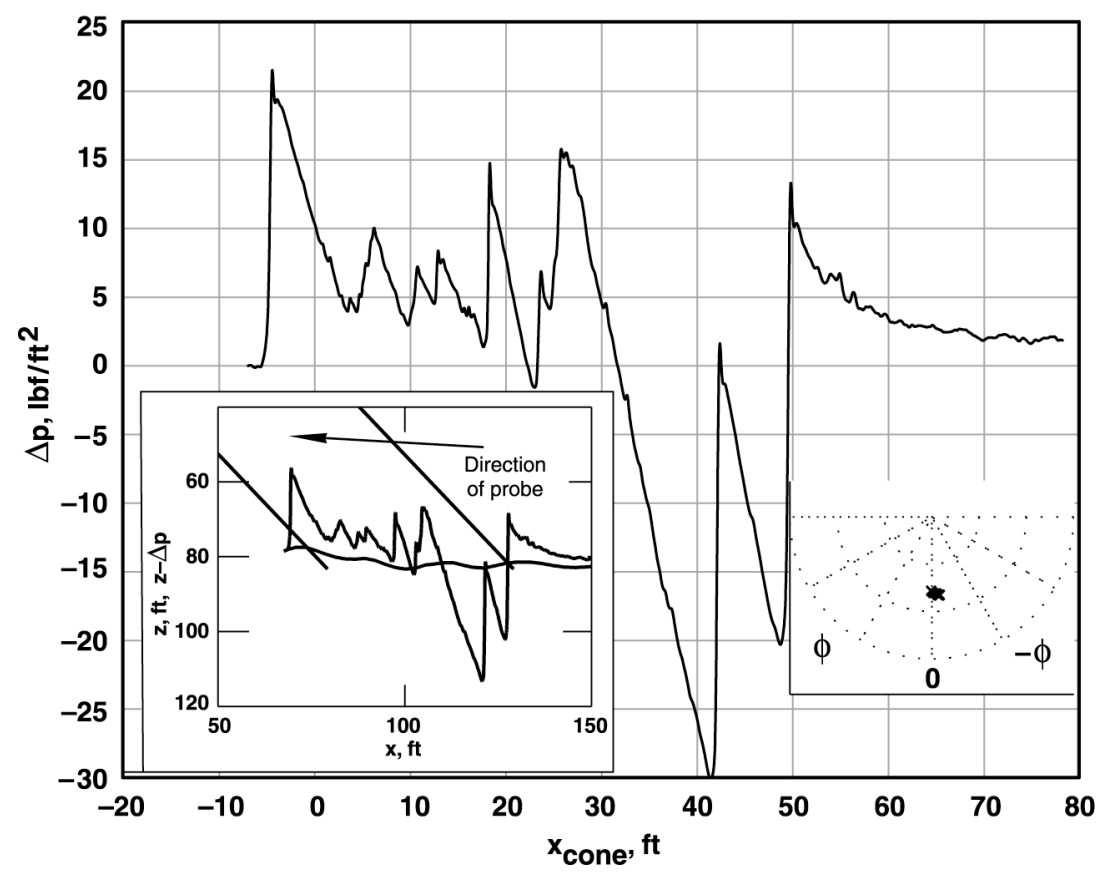

Figure 14. Near-field probing flight data, signature 31-2.

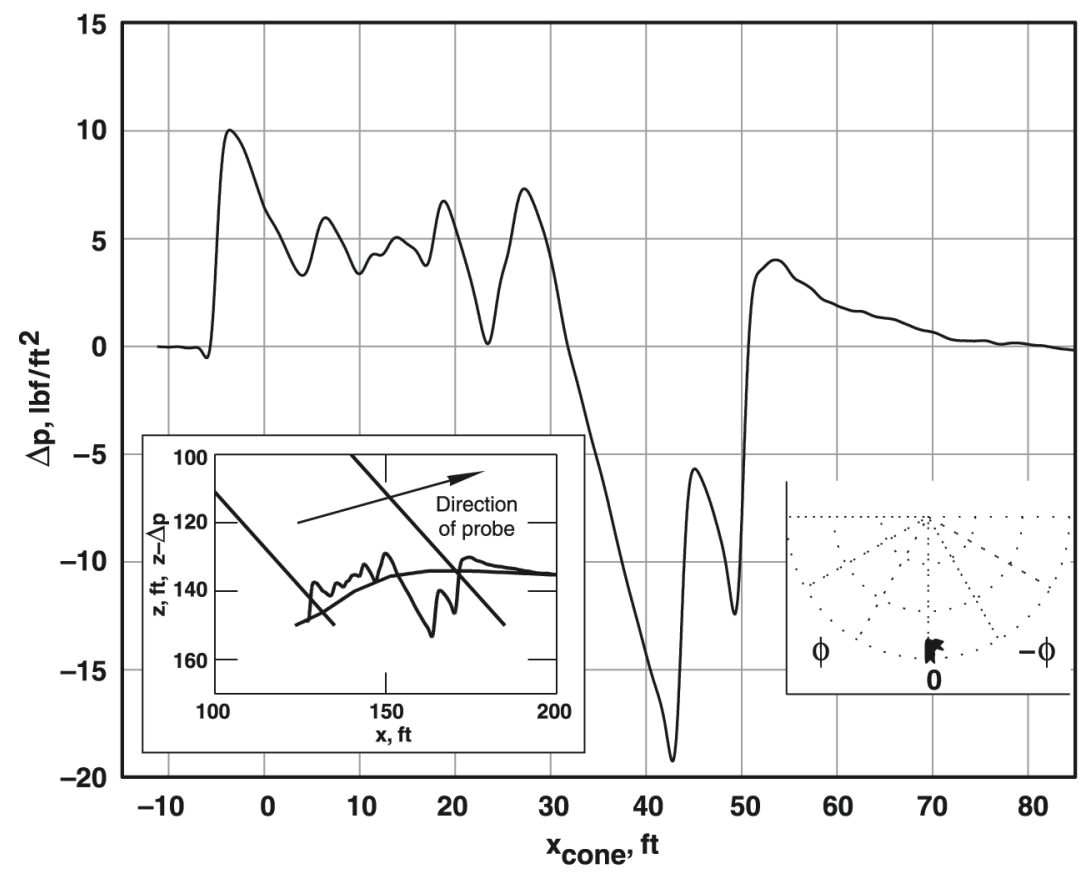

Figure 15. Near-field probing flight data, signature 32-17. 
Notice that there is significant variation in vertical separation $z$ in Fig. 12. During this probing the SSBD aircraft had altitude excursions up and down of up to $130 \mathrm{ft}$, especially while the F-15B aircraft was in the SSBD aircraft tail region. The SSBD aircraft also had slight variations in speed during the probing. The F-15B aircraft pilot attempted to maintain a constant vertical separation during all probings with only visual sighting. The SSBD aircraft motions does factor into the CFD-to-flight comparisons shown below.

There are some features in these probing data that are because of the measurement instrumentation and not the SSBD aircraft flow field. Very slow-rate forward probings tend to have an exaggerated pressure rise at the top of each shock wave. Figure 16 shows the bow shock from Fig. 12 (30-9), both with raw and filtered data. Both the raw and filtered data show the exaggerated pressure rise of $p_{\text {diff }}$ greater than $15 \mathrm{lbf} / \mathrm{ft}^{2}$, and this is thought to be because of interactions of the SSBD aircraft shock wave with the F-15B aircraft noseboom shock wave and boundary layer. Because this feature is very small in longitudinal position, it does not show up during faster overtake speeds where the pneumatic lag of the F-15B aircraft masks the effect. Figure 17 also shows the bow shock from Fig. 11 (30-6), showing the filtered data with an exaggerated pressure drop before the bow shock. This is caused by the backward-forward filter used on a very rapid step input of the shock wave. Neither of these features is real, and are a consequence of the instrumentation and probing technique used.

A signature taken below and to the side of the SSBD aircraft is shown in Fig. 17. In the forebody region there is a different structure than for probings made directly below. There is also less of an expansion region from the wing. This probing was performed at approximately $\phi=-45 \mathrm{deg}$. Since the CFD grid is not as dense at azimuths greater than $30 \mathrm{deg}$, a CFD computation was not run for this signature.

A ground-based pneumatic step-response test was performed on the F-15B aircraft shock-measuring noseboom in order to assess pneumatic lag effects. Analysis of these data is ongoing at this time to generate a model of the pneumatic system. Through optimum deconvolution of this system and extrapolation to flight conditions, refined pressures can be determined that will have sharper shocks, especially for probings that were performed quickly or with the low-rate transducers used in the ISSM and SSBD flight phase.
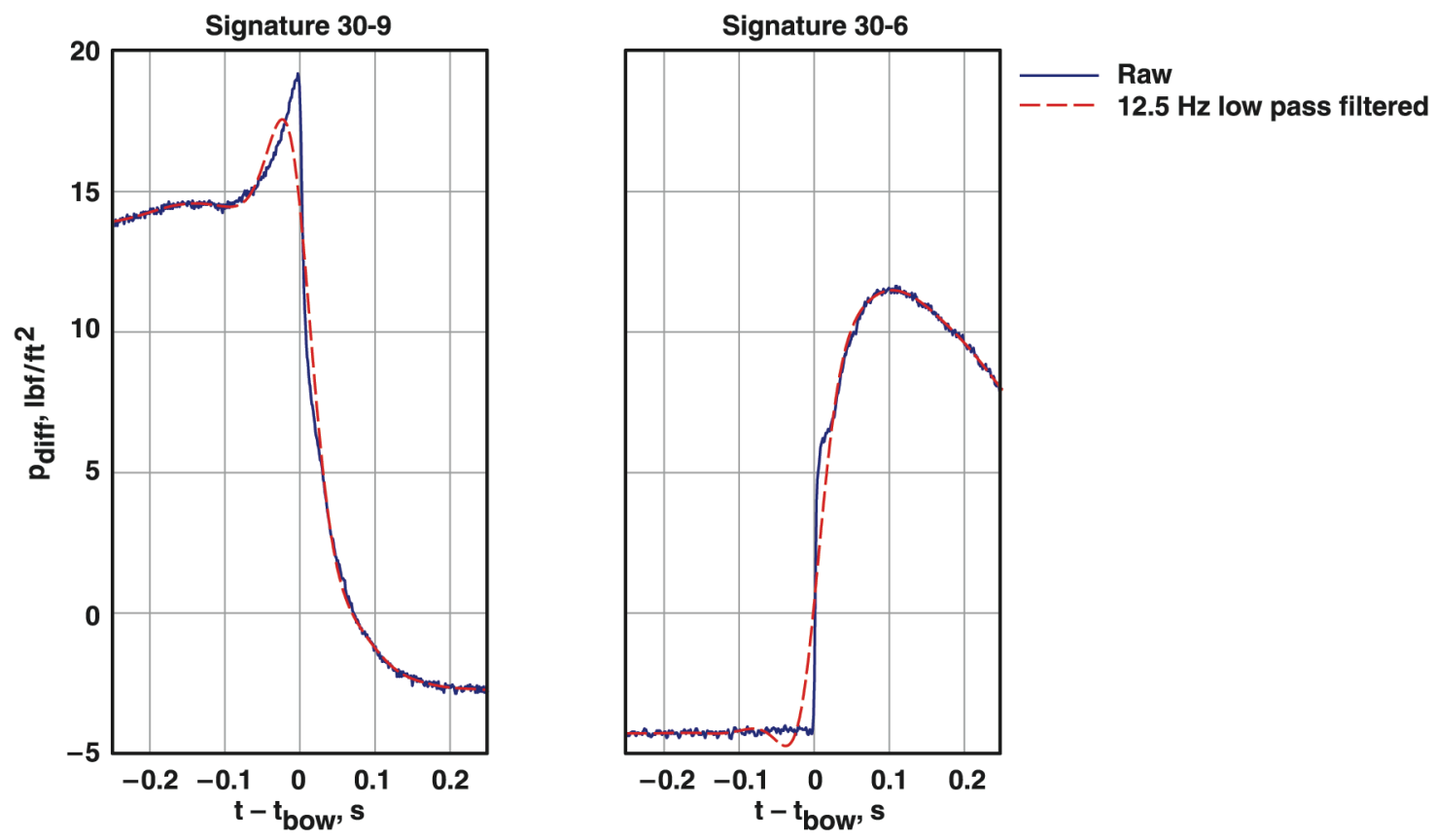

Figure 16. Bow shock measurement anomalies, signatures 30-9 and 30-6. 


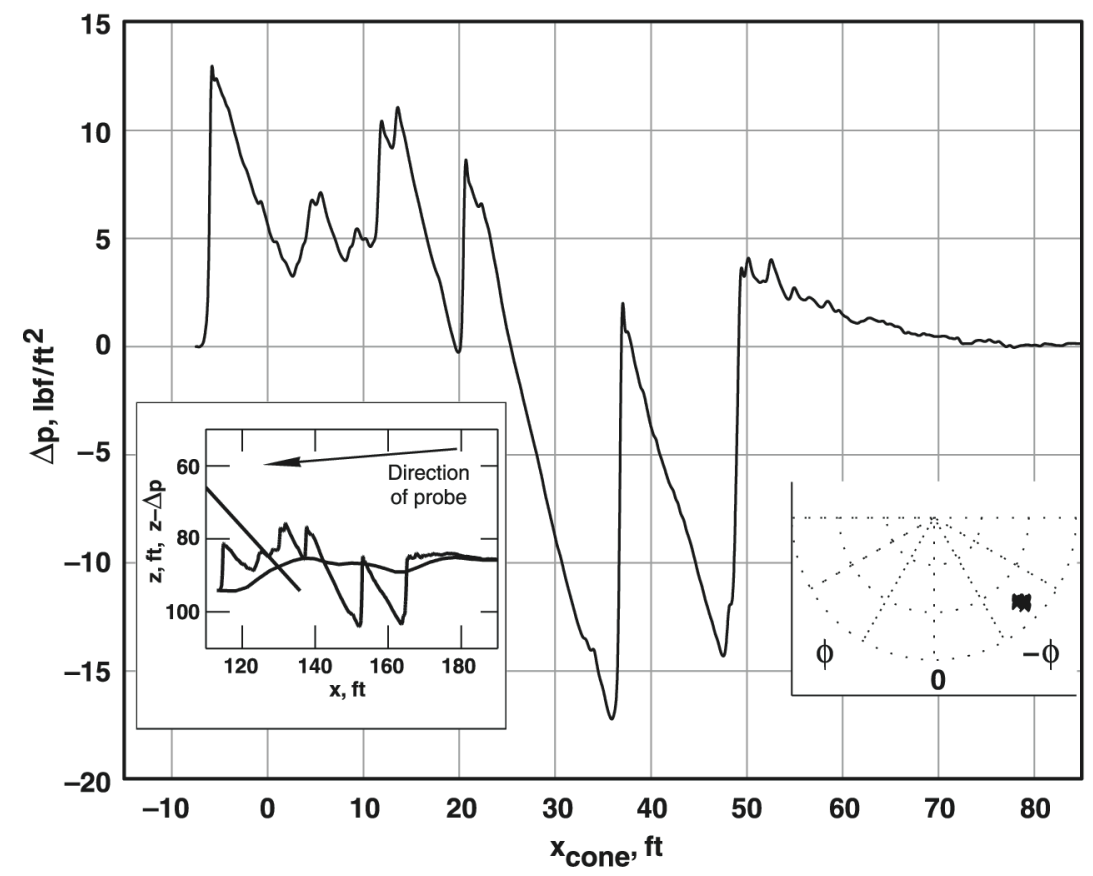

Figure 17. Near-field probing flight data with $\phi=-45 \mathrm{deg}$, signature 33-10.

\section{B. The L-23 Sailplane Far-field Probing Flight Data}

Figure 18 shows far-field probing flight data from the sailplane from one flight. The pressures are plotted as a function of the stationary observer time, given in Eq. (10). The SSBD aircraft flew over the sailplane, followed by the baseline F-5E aircraft approximately $45 \mathrm{~s}$ later. Figure 19 shows a schematic of far-field measured signatures. The sailplane was in perfect position to have its measured signature also hit the center of the ground array. Both the incident signature from each aircraft can be seen in Fig. 18, as well as the signatures that have reflected off of the ground and propagated upward to the sailplane. The reflected signatures show more effects of turbulence because of the double pass through the bottom $6,000 \mathrm{ft}$ of the atmosphere.

In order to solve Eq. (10), the propagation time from each supersonic aircraft to the sailplane is needed. The flight conditions of both aircraft and the atmospheric reference data from this flight were input into PCBoom $4,{ }^{21}$ and the "ground" altitude was selected as the sailplane geometric altitude above mean sea level, $Z_{m s l}$. The SABER measured the time of the bow shocks, and the DGPS data from the sailplane was used to find the sailplane location at these times. The sailplane location was input into PCBoom4, and the times of sonic boom generation and sonic boom impact were calculated. Consistency between the flight data and PCBoom4 simulation can be determined by the agreement of the sonic boom impact time. For the SSBD aircraft pass, the PCBoom4 prediction and SABER-measured $t_{\text {bow }}$ agreed to within $0.23 \mathrm{~s}$, and for the baseline F-5E aircraft the times agreed to within $1.61 \mathrm{~s}$, which is judged to be excellent agreement. These time differences are illustrated in Fig. 19 by the offsets between the incident ray paths and the DGPS incident boom origins. It was anticipated that the F-5E aircraft data would not be as accurate as the SSBD aircraft data, as the SSBD aircraft had an airdata system calibrated over many flights, while the F-5E aircraft flight conditions are inferred from DGPS and atmospheric reference data on each flight alone. Also, Fig. 18 shows the flight conditions of the two aircraft when the signatures were generated, with the F-5E aircraft at a significantly higher Mach number than the SSBD aircraft. This is also seen as converging incident rays in Fig. 19. The F-5E aircraft cockpit Mach meter was not calibrated to research accuracy levels, so the F-5E aircraft Mach meter probably was reading too low.

As the sailplane-measured far-field signatures are quite like the ground-measured signatures, more far-field data is presented in Ref. 8 . 


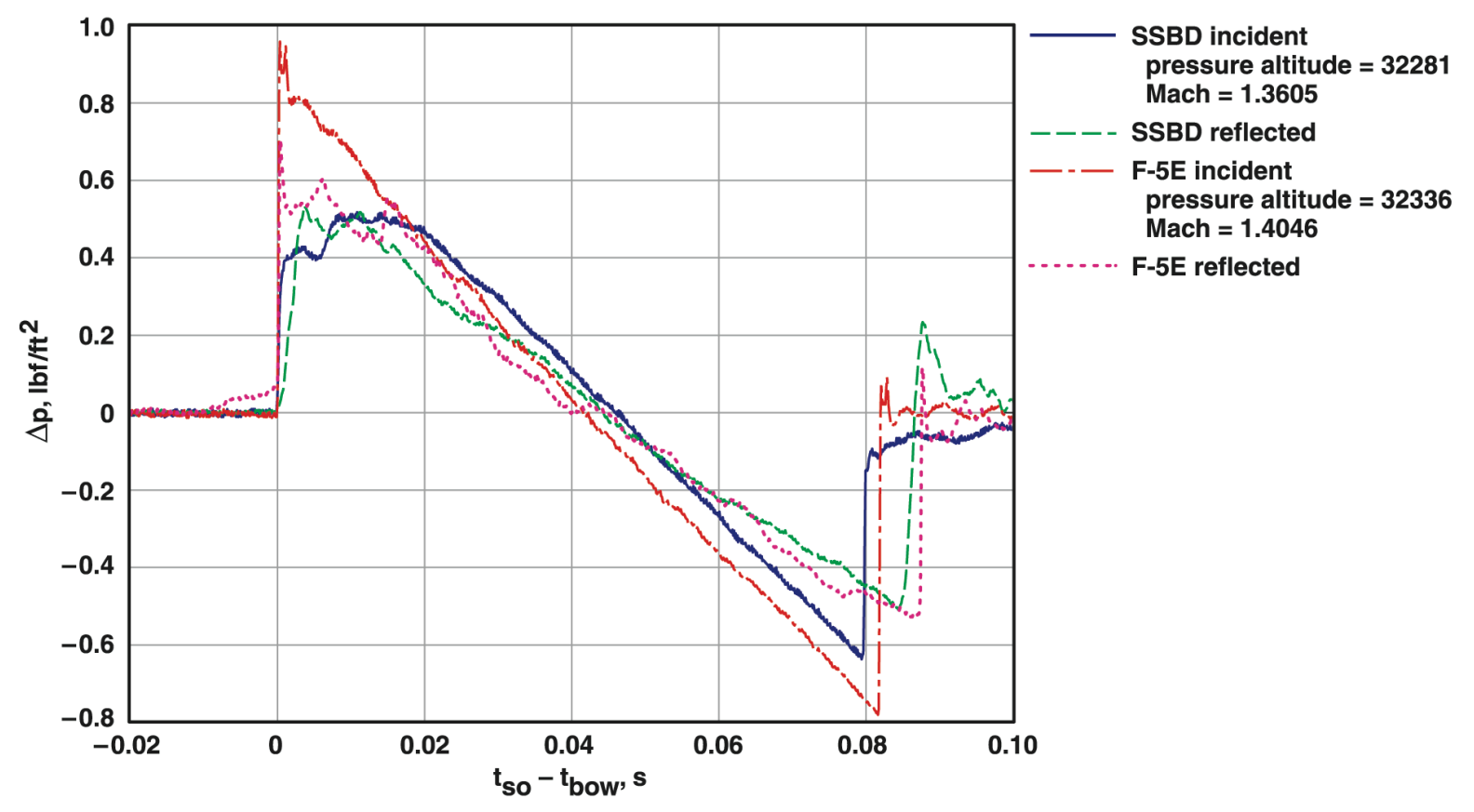

Figure 18. Sailplane far-field probing flight data for flight 21, incident and reflected for SSBD (sailplane $Z_{\mathrm{msl}}=7987 \mathrm{ft}$ ) and baseline $F-5 E$ (sailplane $Z_{\mathrm{msl}}=\mathbf{7 8 2 1} \mathrm{ft}$ ).

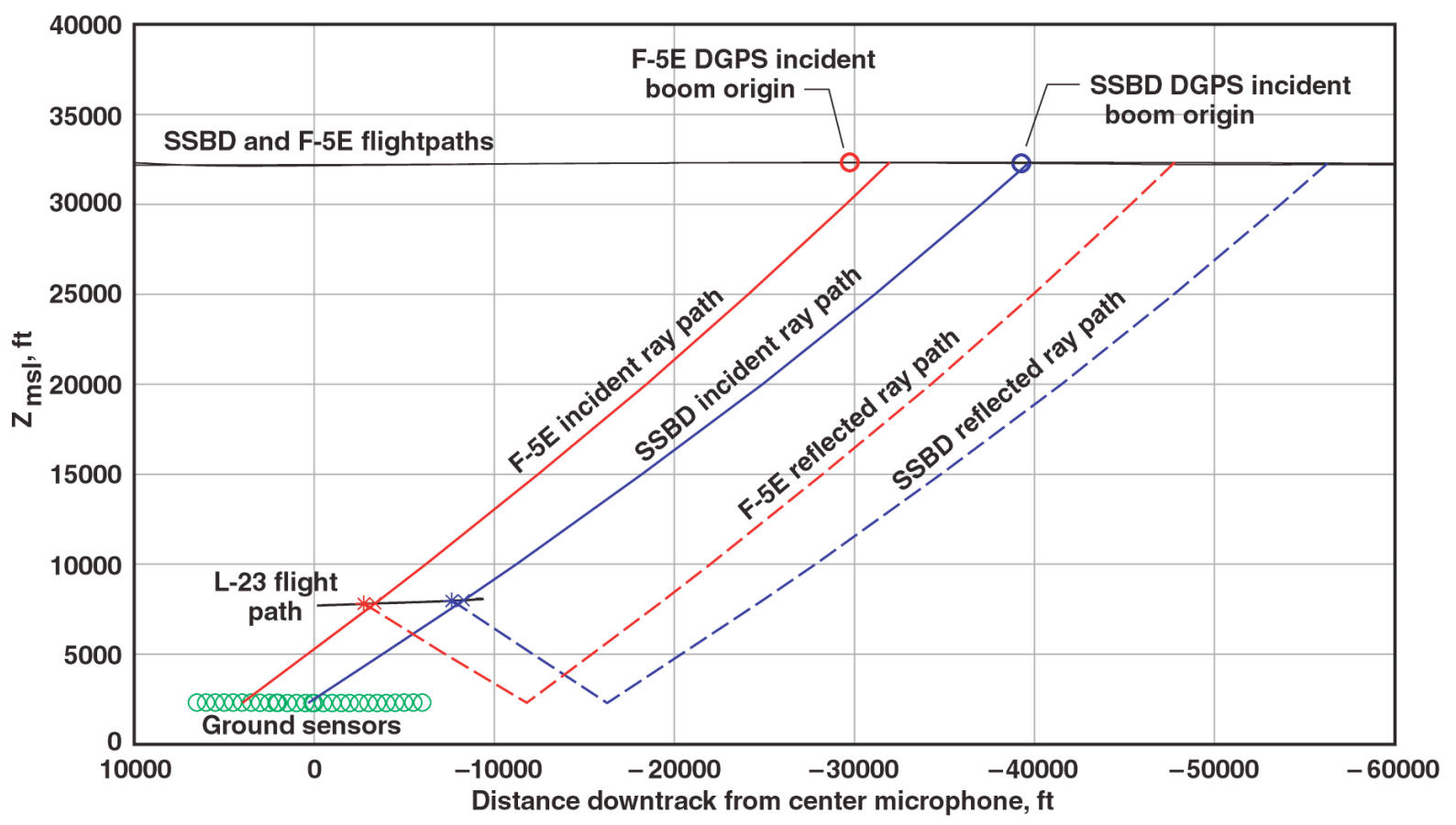

Figure 19. Schematic of far-field measured signatures for flight 21, aircraft flying right to left. 


\section{Computational Fluid Dynamics}

The CFD code used in the comparison was the Northrop Grumman-proprietary GCNSfv code. ${ }^{11}$ It is a structured, implicit, finite volume code, based on the NASA Ames Research Center Three Dimensional (ARC3D) algorithm. ${ }^{22}$ For this analysis, it was used in the inviscid mode, since viscous effects were found to be negligible. ${ }^{10}$ The best flight-measured signatures were determined, and CFD solutions were run at the corresponding flight conditions (Mach number, altitude, angle of attack, and inlet corrected mass flow given in Table 2).

A great deal of wisdom and experience gained from the ISSM flight test ${ }^{10}$ was used in the CFD analysis for these flight test comparisons. Figure 20 shows the basic grid topologies that were replicated from the ISSM CFD runs with more grid points, consisting of:

- Shock-aligned grid structure along the Mach 1.4 cones

- Very highly-resolved near-field grids about the aircraft

- Highly-resolved mid-field grids overset into the lower side of the flowfield

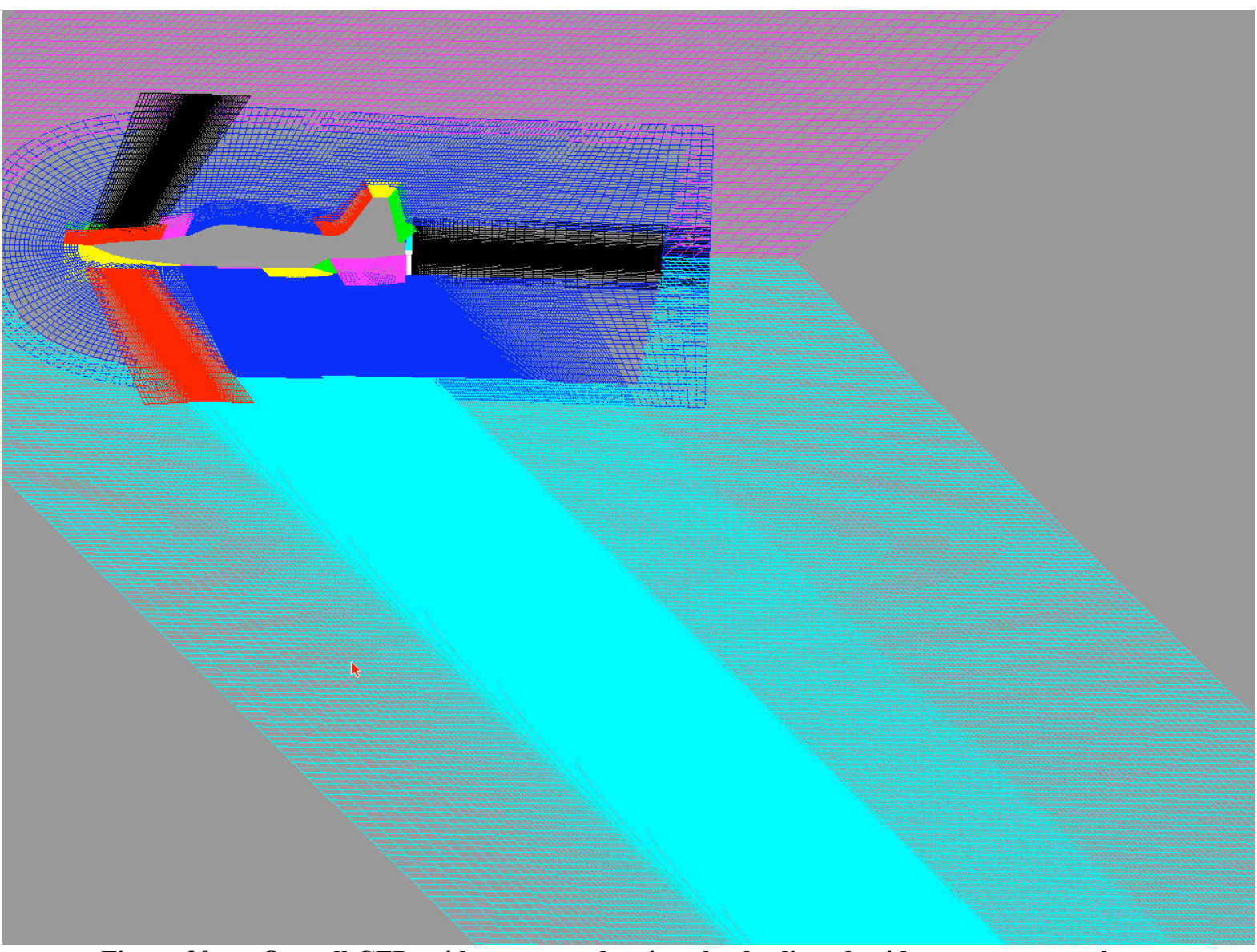

Figure 20. Overall CFD grid structure showing shock-aligned grids on symmetry plane. 
Figure 21 shows a detailed image of the near-field grid structure. The total grid point count was approximately 17.1 million points, with 7.1 million points in the near field (within 0.5 body length), and another 10 million points in the midfield ( 0.5 to 2.5 body lengths), mostly clustered toward the lower side of the aircraft.

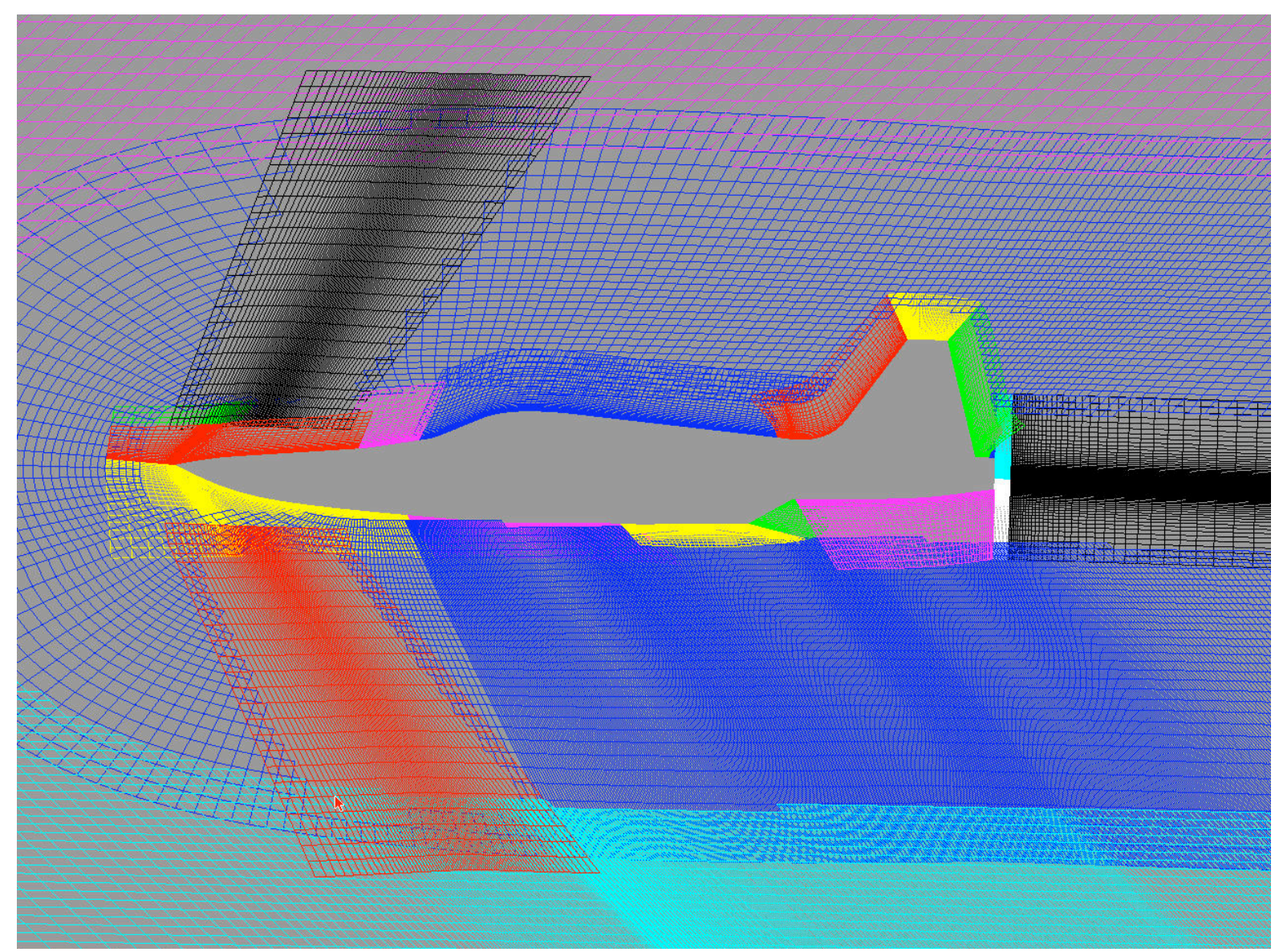

Figure 21. Detail of near-field CFD grid. 
Since the F-15B aircraft probing passes were not straight-and-level relative to the SSBD aircraft, the DGPS-derived flightpath was interpolated into the CFD flowfield. Figure 22 shows the F-15B probing aircraft flightpath in relation to the CFD-computed flowfield. The pressures from the CFD flowfield were then interpolated along that flightpath, and compared to the actual flight test data. Note that interpolation of the F-15B aircraft flightpath also took into account the lateral variation of the F-15B aircraft relative to the SSBD aircraft flightpath. Figure 23 depicts this as the width of the grey ribbon.

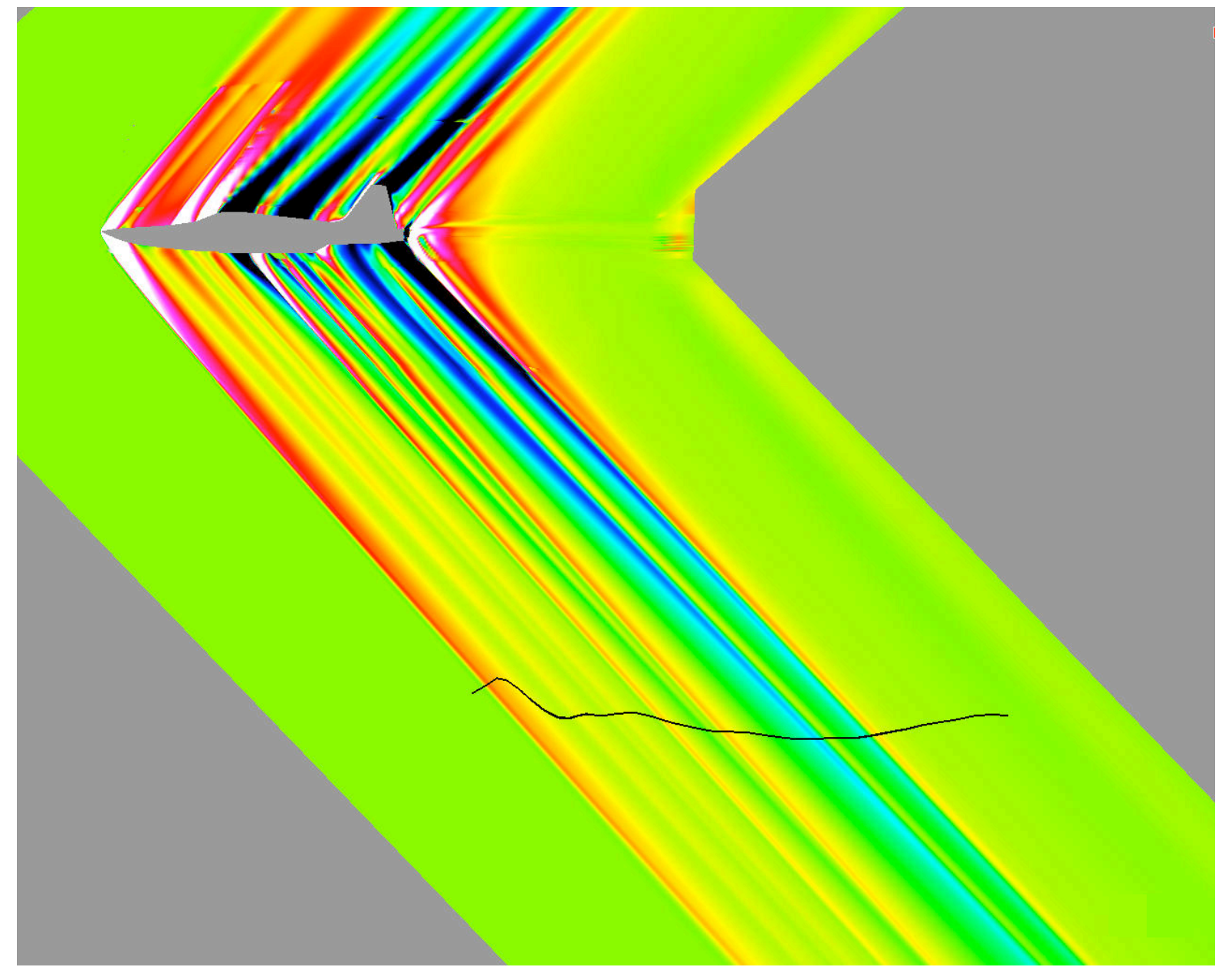

Figure 22. F-15B probing flightpath in relation to CFD-computed flowfield on symmetry plane, signature 30-11. 


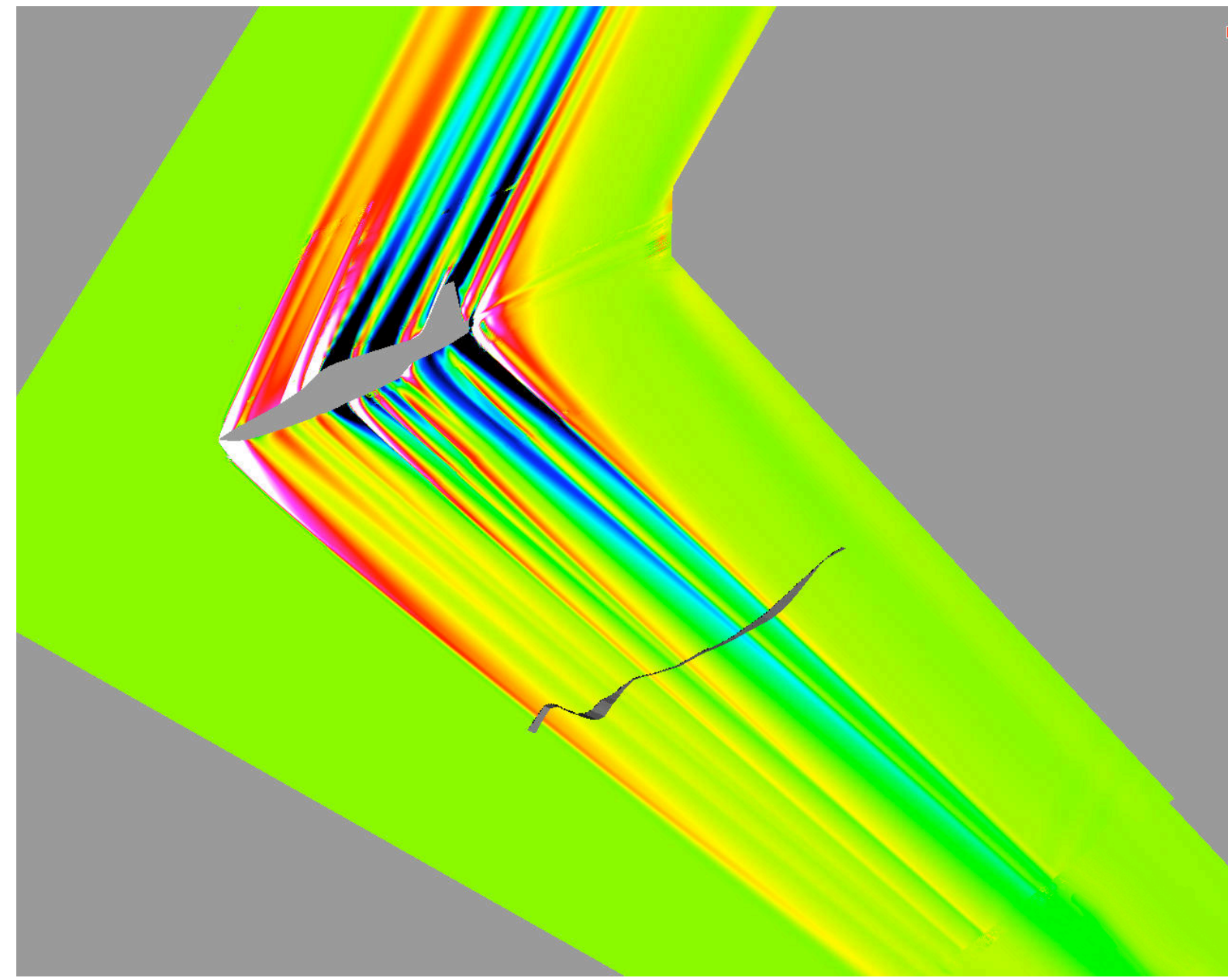

Figure 23. F-15B probing flightpath showing transverse variation in flight, signature 30-11. 
Figure 24 shows interpolated CFD-derived pressures along with the flight-measured pressures for signature 30-11. The computed pressures capture the discrete shocks in the flowfield quite well. Individual shocks from the nose, forebody, inlet, wing, horizontal tail, and the corresponding expansion regions, line up exceptionally well with the flight-test data. Pressure magnitudes match quite well for the inlet, wing, and tail shocks. The overall signature agreement between CFD and flight is excellent.

However, the bow shock and the minor shocks caused by the forebody are underpredicted in magnitude in the CFD solution. Tracing these shock waves toward the aircraft in the CFD solution, their origins can be determined. The forward two minor shocks are from the slope discontinuity on the upper surface of the forebody. The third minor shock is from the aircraft canopy. The computed strength of these minor shocks did not change appreciably as the grid density was increased on the upper surface to the 17.1 million grid point solutions presented in this paper. It should be noted that the CFD analysis did not include geometry features that were assumed to be insignificant, such as nose gear door gaps, noseboom, total temperature probes, etc. It is possible that these have more of an effect than assumed.

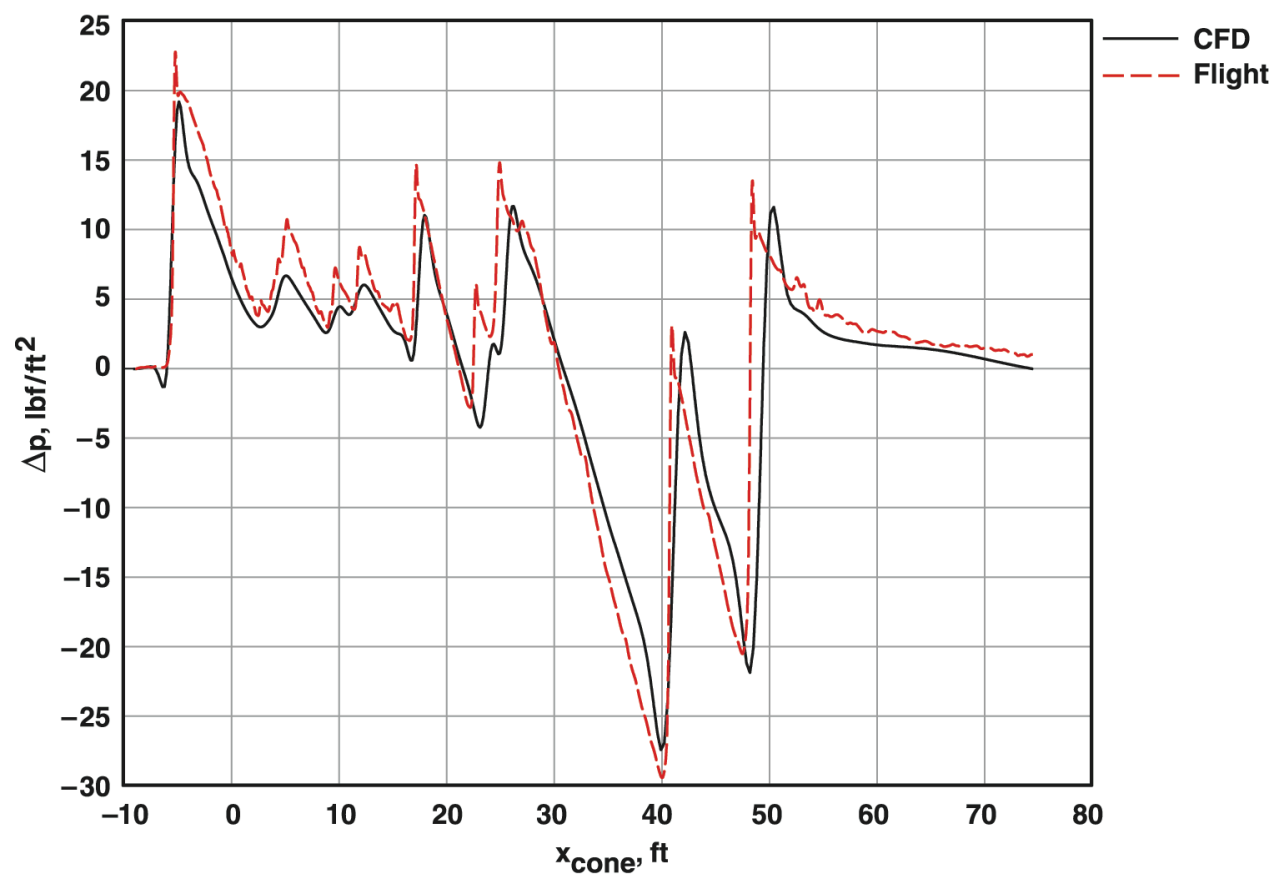

Figure 24. Pressure signature comparison between flight test and CFD, signature 30-11. 
Another flight test signature provided an overall good comparison, as well. Figure 25 shows the flightpath for signature 31-2, and Fig. 26 shows the pressures along this path. Notice that the general shock structures are similar, but seem to be offset in position. Figure 27 shows that by arbitrarily shifting the CFD data longitudinally 5 in., the shock locations are well matched. It is difficult to determine the accuracy of the DGPS data for relative position, but errors on the order of one foot are quite possible, and PNAV root mean square errors of this size were seen during this probing. Work is ongoing to assess the accuracy of DGPS-derived relative position using optical techniques. ${ }^{23}$ Additionally, CFD numeric dissipation can be responsible for shock location offsets. In Fig. 27 excellent agreement is seen for the major shock structure locations with the 5-in. CFD translation, but as before, the bow and forebody shocks are underpredicted. The shocks at the leading and trailing edge of the wing are slightly underpredicted by CFD, which could be because of a slight underestimation of angle of attack.

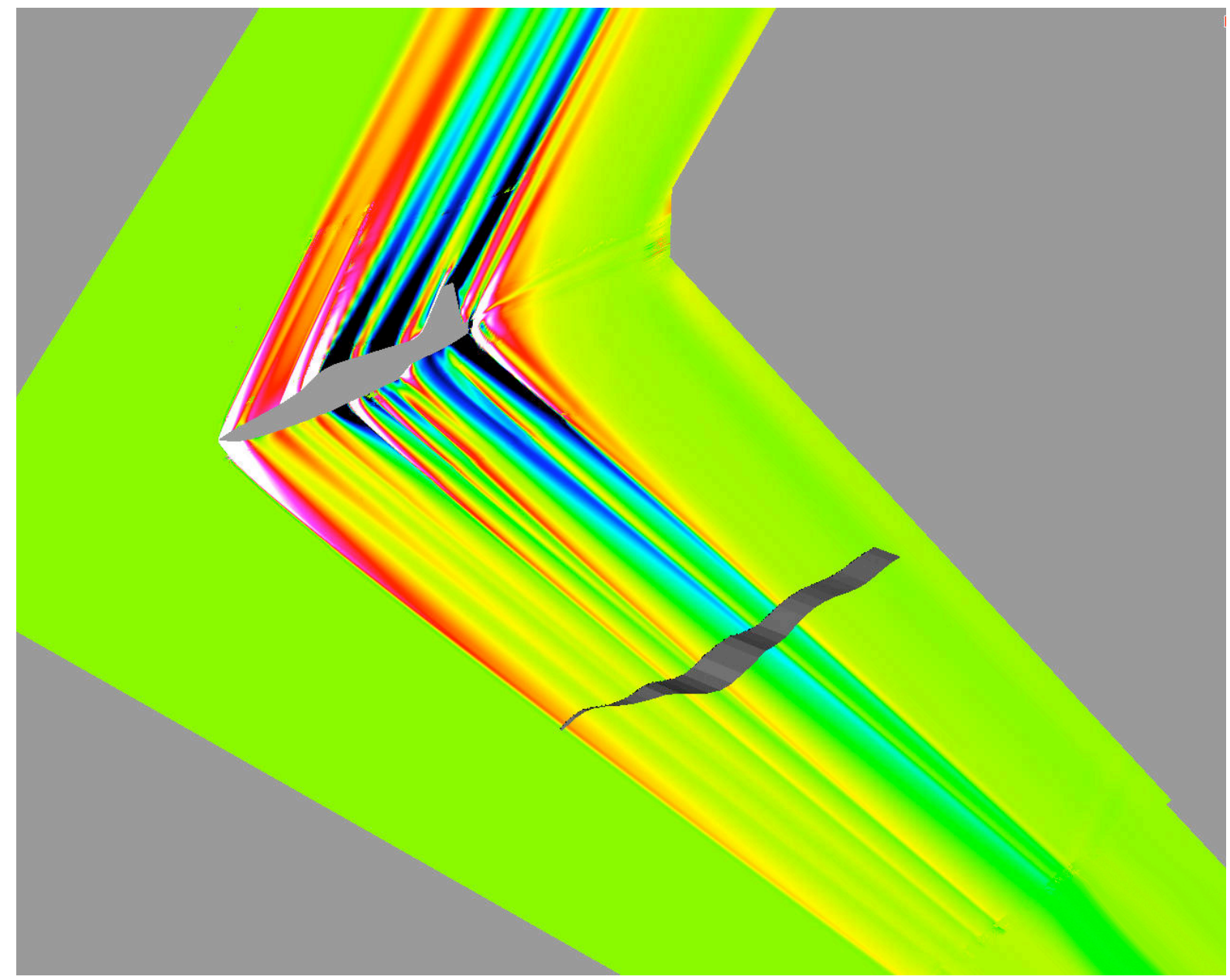

Figure 25. F-15B probing flightpath showing transverse variation in flight, signature 31-2. 


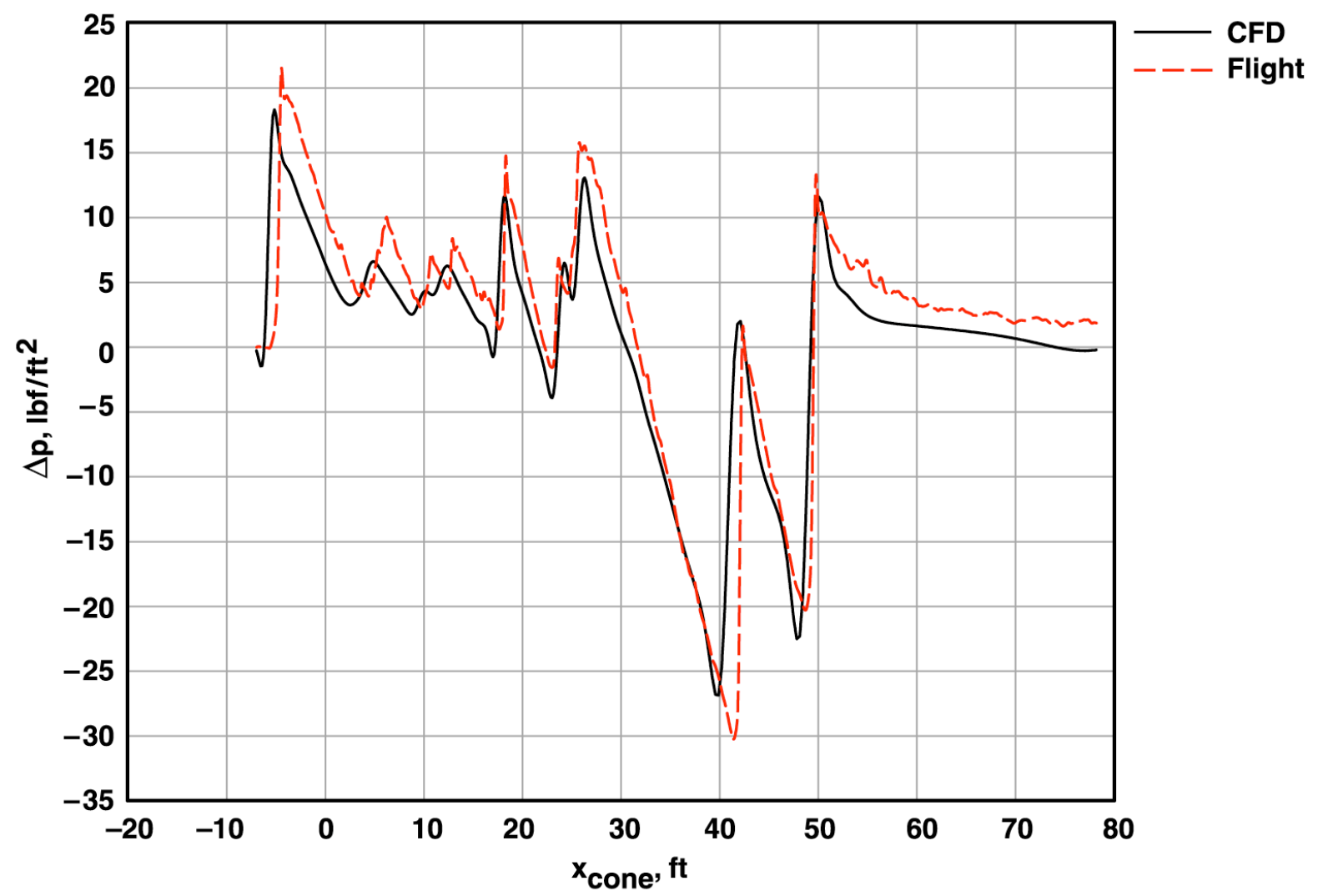

Figure 26. Pressure signature comparison between flight test and CFD, signature 31-2.

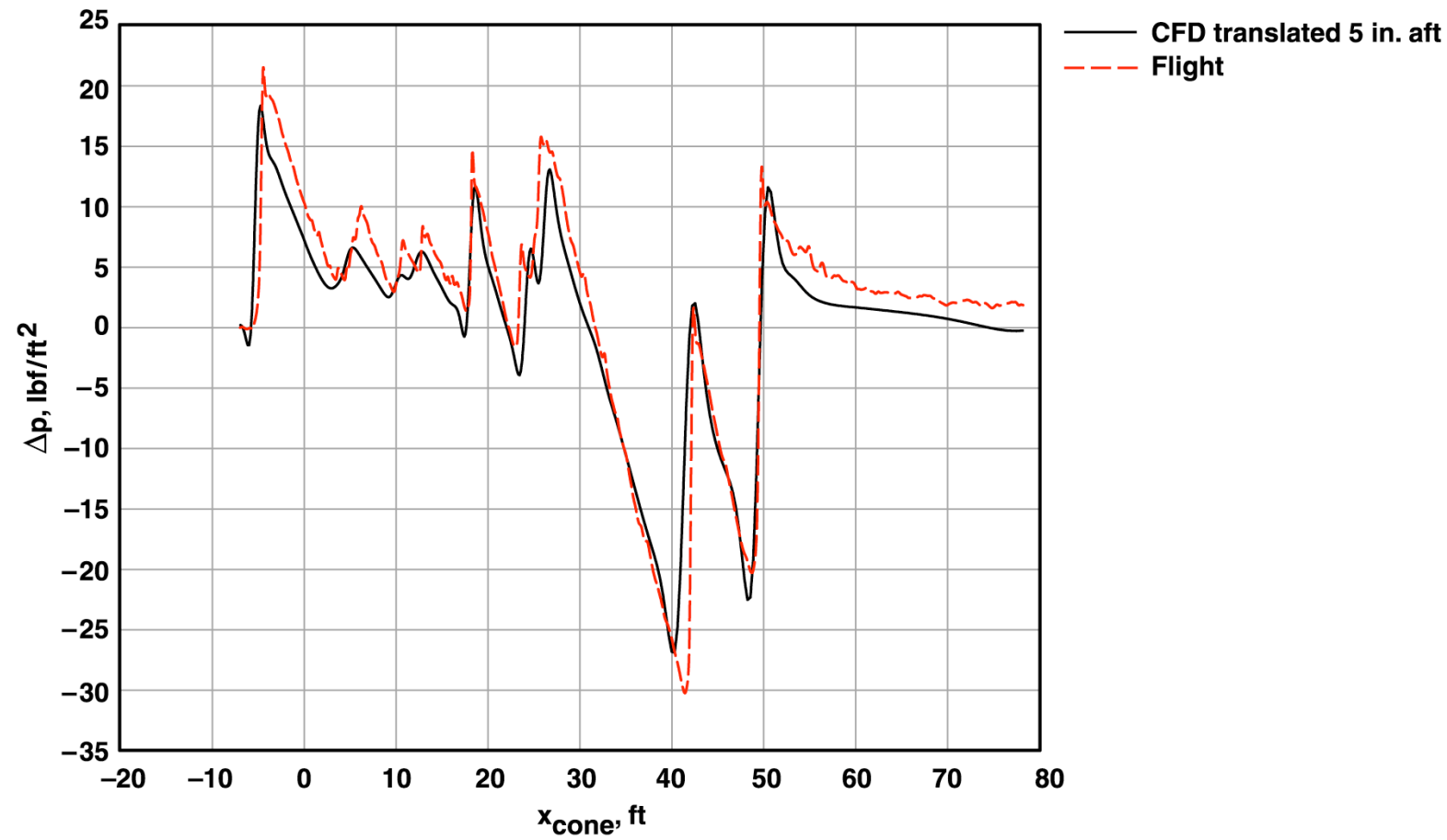

Figure 27. Pressure signature comparison between flight test and CFD, CFD translated to match flight shock locations, signature 31-2. 
Even when both the SSBD and F-15B aircraft were unsteady during probing, excellent agreement between CFD and flight data was achieved. Figure 28 shows the relative separation variation between aircraft, and Fig. 29 shows the pressure signature comparison. Magnitudes and locations of shocks show excellent agreement without CFD translation, with a slight offset in the final recompression shock location. While probing the tail region for this signature, the SSBD aircraft had its fastest climb rate of the probing, with altitude excursions of $130 \mathrm{ft}$.

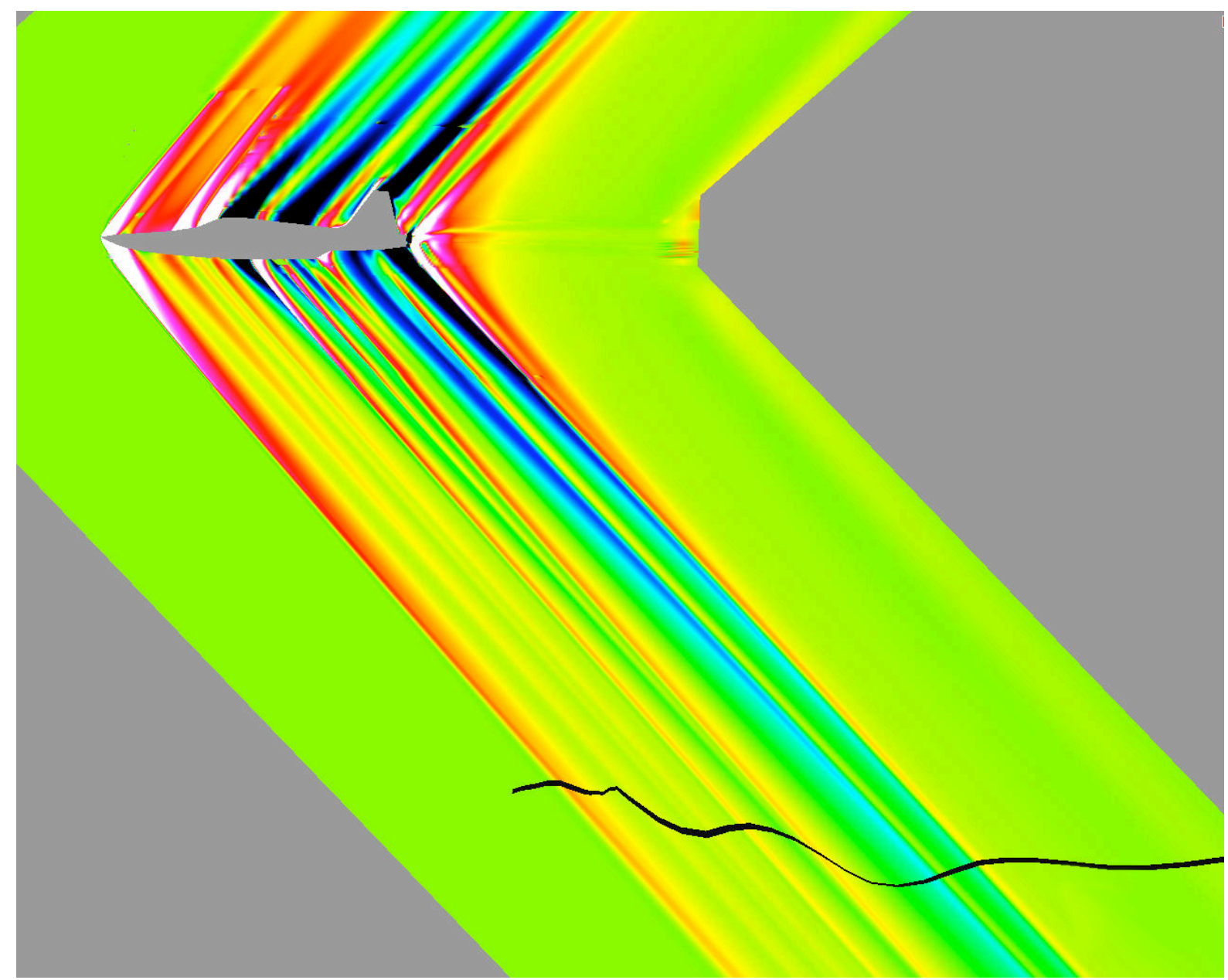

Figure 28. F-15B probing flightpath in relation to CFD-computed flowfield on symmetry plane showing variation in vertical distance, signature 30-9. 


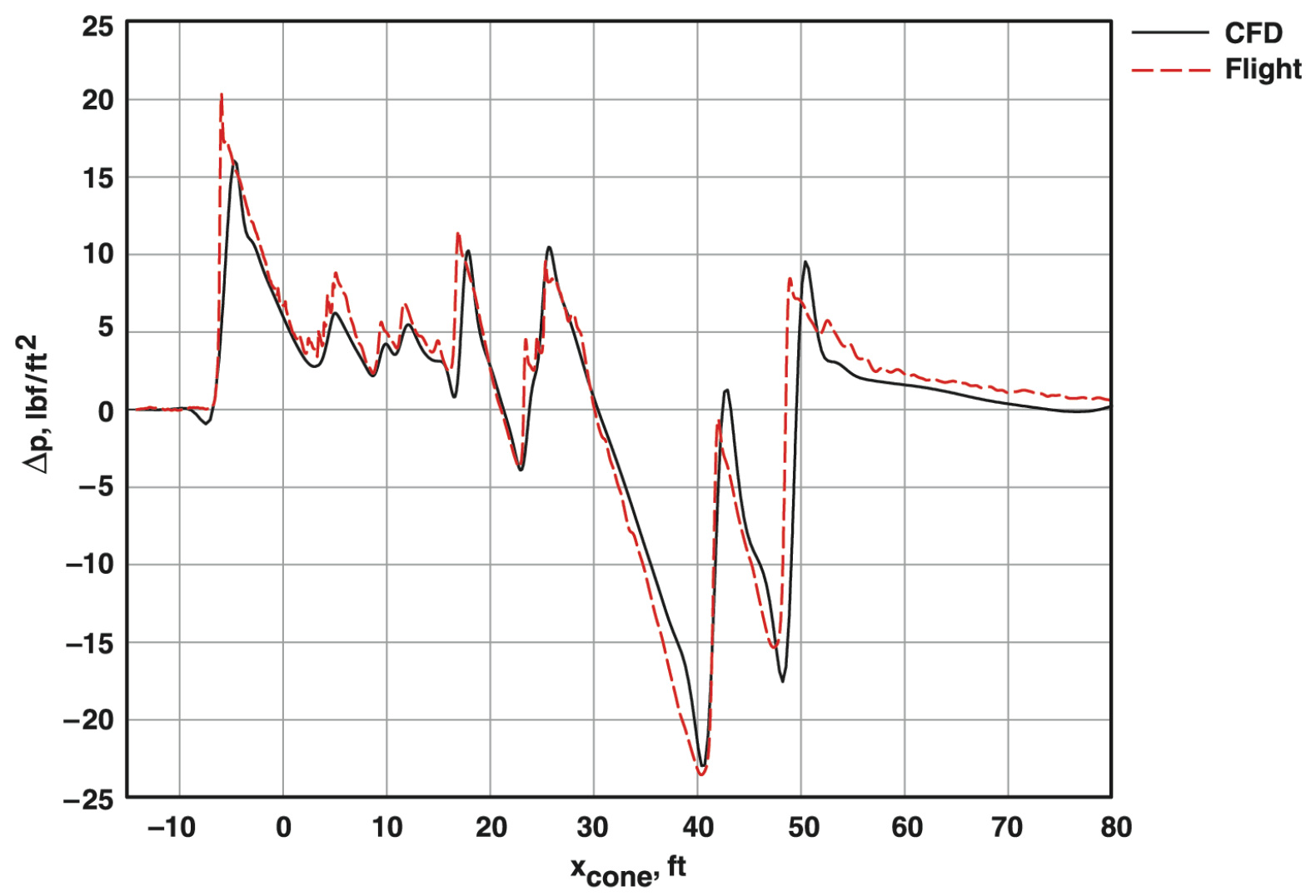

Figure 29. Pressure signature comparison between flight test and CFD, signature 30-9.

Figures 30-32 show that excellent agreement was achieved for three other signatures after slight shifting of the CFD data. All of the SSBE flight phase data analyzed had shifts of $2 \mathrm{ft}$ or less. For signature 8-2 (Fig. 32) during the SSBD flight phase, 40 in. of translation was needed. This flight had fewer GPS satellites visible than the other flights, and the GPS satellite reception was lost about one minute before the probing, and again after probings were complete. This resulted in a PNAV root mean square error of about $3 \mathrm{ft}$, close to the 40 in. of translation required. Using PNAV with integer ambiguities allowed to float resulted in up to 60 in. of shifting needed, while using GPS processing software without base station data necessitated up to $120 \mathrm{in}$. of translation. Optical measurements in future near-field probing efforts may be required to resolve these slight position offsets, but the small positional errors shown should not be significant when the signature propagates down to the ground. The signatures in Figs. 30-32 were probed at a faster rate than the other signatures presented, so the flight data is somewhat rounded, underestimating the peak pressures. Using the expansion regions to infer local maximum pressure peaks for each shock wave, the CFD again underpredicts the bow and forebody shock strengths. Propagating both the CFD and flight near-field pressure signatures to the ground and comparing these results to measured ground-level signatures is the next step in validating the CFD prediction codes. Even before this validation is performed, we can see in Fig. 2 that the GCNSfv code was successfully used in the design of the SSBD aircraft, producing a shaped sonic boom to ground level. 


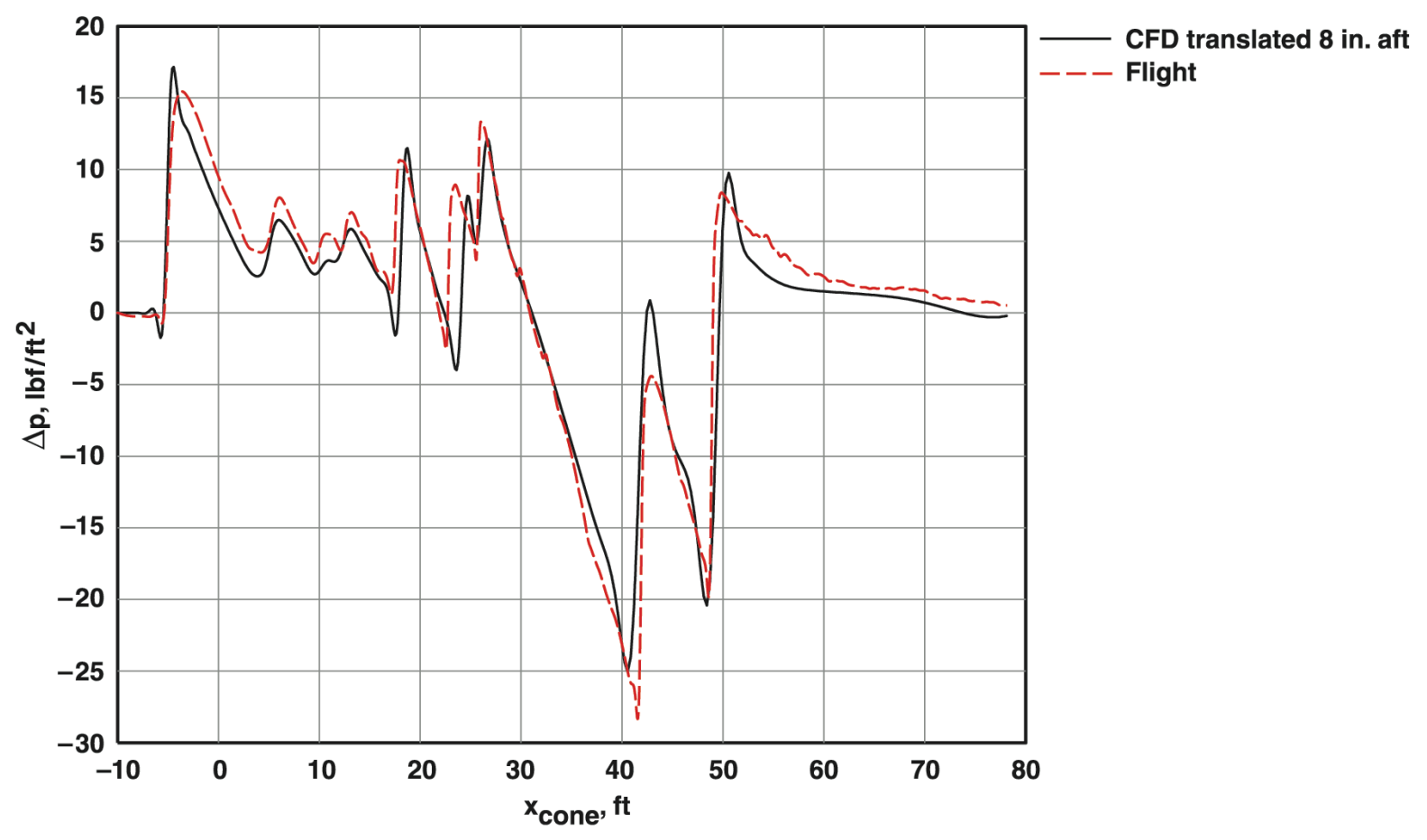

Figure 30. Pressure signature comparison between flight test and CFD, CFD translated to match flight shock locations, signature 30-6.

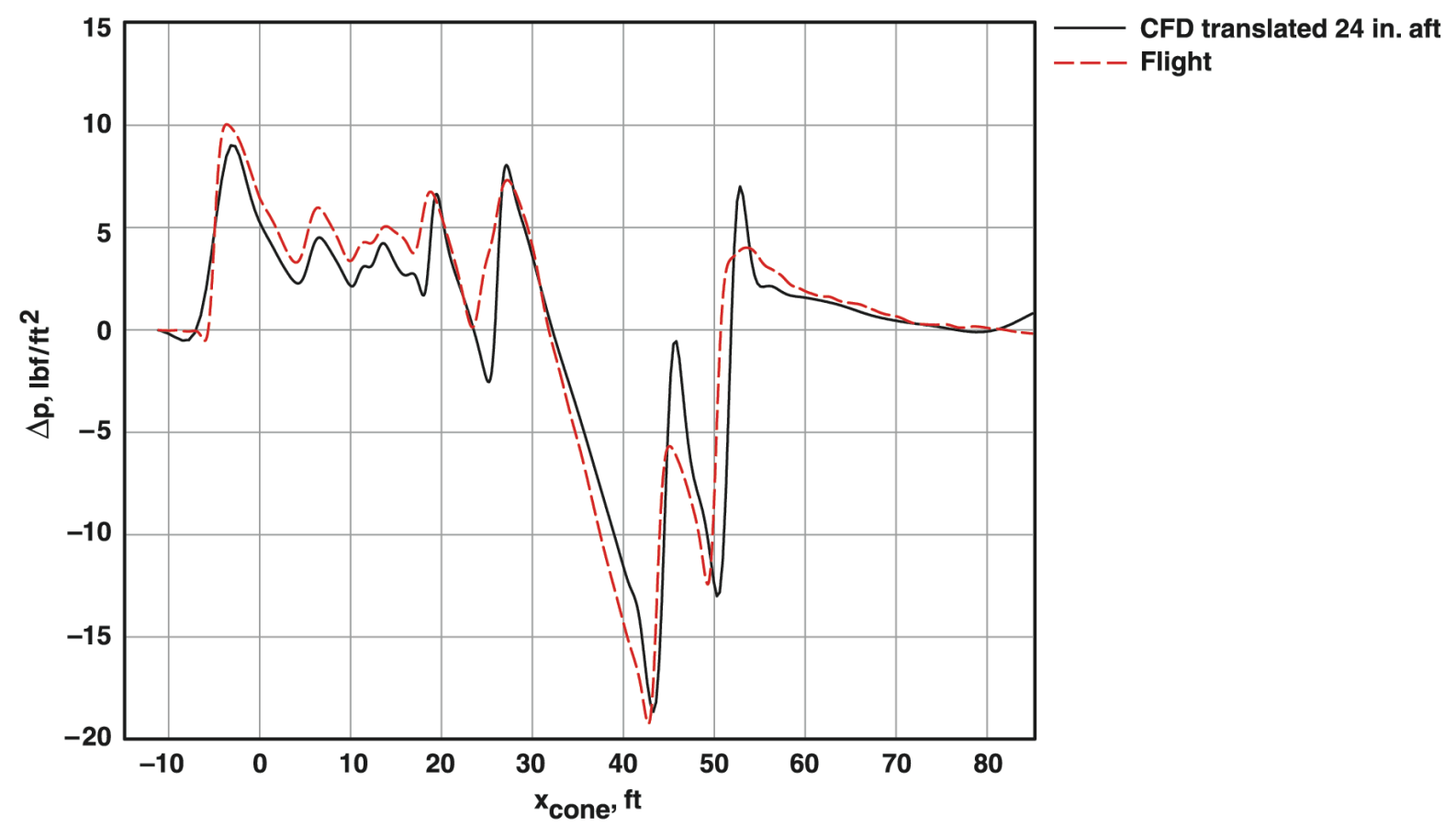

Figure 31. Pressure signature comparison between flight test and CFD, CFD translated to match flight shock locations, signature 32-17. 


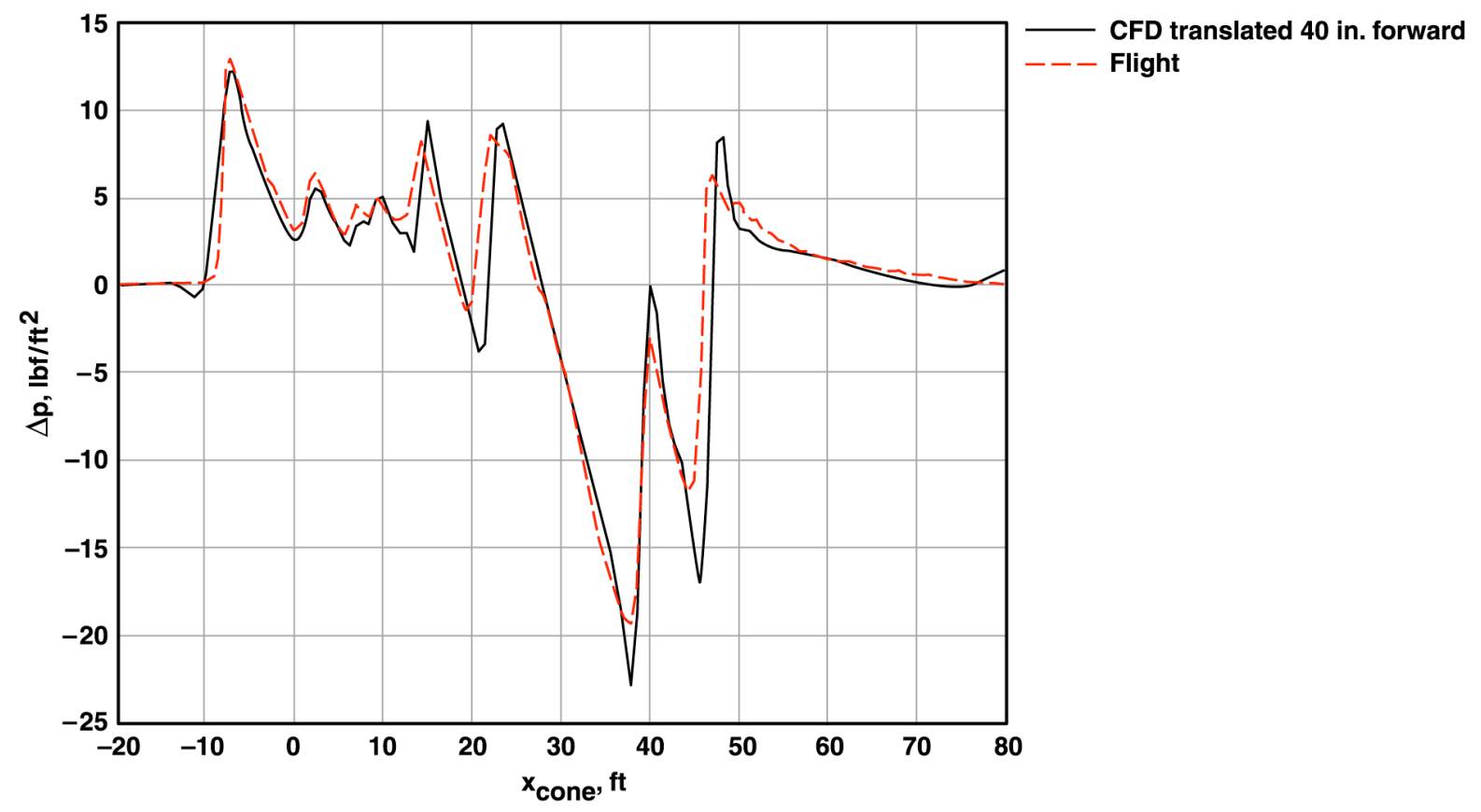

Figure 32. Pressure signature comparison between flight test and CFD, CFD translated to match flight shock locations, signature 8-2.

\section{Conclusion}

Airborne measurements were taken of the Shaped Sonic Boom Demonstration aircraft and baseline F-5E aircraft to measure their shock signatures. The flight conditions of these aircraft were determined through atmospheric reference analysis and airdata calibration to very high accuracy. An F-15B aircraft performed 68 near-field probings of the Shaped Sonic Boom Demonstration aircraft over six flights at distances of 60 to $720 \mathrm{ft}$. Very detailed signatures were obtained showing shock waves from the nose, forebody, inlet, leading edge extension, wing, and tail. An L-23 sailplane measured far-field incident and reflected shock waves over 13 flights with much lower turbulence effects than what can occur on ground-level sensors. Boom propagation code data show excellent matches of far-field data in location and time. These airborne measurements of the Shaped Sonic Boom Demonstration aircraft are a unique and important database that will be used to validate design tools for a new generation of quiet supersonic aircraft.

Several observations were made of airborne shock-measuring techniques. For all measurements, accurate global positioning system-based timing is essential for data correlation with multiple aircraft. Atmospheric analysis and differential global positioning system data can give high accuracy airdata calibration, but individual rawinsondes can have very large errors. While onboard-recorded data tends to be cleaner than telemetered data, failure in the onboard recording system could result in loss of mission. Having both onboard and telemetered data gives redundancy for data collection, which saved several flights on this program. Flight activities that are compressed in time without allowing data analysis between flights run the risk of loss of mission-critical data. While data was not lost on this program because of time constraints, there was some data degradation in flight- and ground-data quality that could have been rectified with a slower pace. Weather and contract limitations necessitated the pace that was taken.

Specific observations to the near-field probing technique were made. Some small anomalies in these near-field signatures are seen looking like overshoots. Shock-measuring plumbing design requires careful sizing, with some results measured on the lag tank during the first flight phase unexpected by simulation. Real-time monitoring of measured shock waves is essential for efficient shock wave probing. For the far-field measurements using the sailplane, it was observed that conventional static pressure measurements suffer from an organ-pipe resonance effect. Having a high-quality microphone with a bullet nose and wind screen in clean flow yielded superior results. 
The computational fluid dynamics (CFD)-to-flight comparisons were good to excellent, even with nonlevel and nonsteady probings. At times there were slight shock position differences between the flight and CFD data that are consistent with differential global positioning system errors, but the shifted CFD data matched the flight data well. The shock strengths forward of the inlet shock were underpredicted by CFD, and the underprediction is thought to be caused by minor geometry features not modeled in the CFD grid. The slight differences in shock location between CFD prediction and flight data are not considered significant. It is unknown if the underprediction of bow and forebody shock strength is significant, but this can be determined by propagating these near-field signatures to ground level and then comparing to ground-level measurements of the Shaped Sonic Boom Demonstration aircraft sonic boom. It is known that the Shaped Sonic Boom Demonstration aircraft, designed with CFD predictions and sonic boom propagation codes, did repeatedly achieve a shaped sonic boom to ground level.

\section{Acknowledgments}

The Shaped Sonic Boom Demonstration flight phase was funded by the Defense Advanced Research Projects Agency, and the Shaped Sonic Boom Experiment flight phase was funded by the National Aeronautics and Space Administration.

\section{References}

${ }^{1}$ McLean, F. E., “Some Nonasymptotic Effects on the Sonic Boom of Large Airplanes,” NASA TN D-2877, 1965.

${ }^{2}$ McLean, F. E., Carlson, H. W., and Hunton, L. W., "Sonic-Boom Characteristics of Proposed Supersonic and Hypersonic Airplanes," NASA TN D-3587, 1966.

${ }^{3}$ George, A. R., "Lower Bounds for Sonic Booms in the Midfield," AIAA Journal, Vol. 7, No. 8, 1969, pp. 1542-1545.

${ }^{4}$ George, A. R., and Seebass, R., "Sonic Boom Minimization Including Both Front and Rear Shocks," AIAA Journal, Vol. 9 , No. 10, 1971, pp. 2091-2093.

${ }^{5}$ Seebass, R., and George, A. R., "Sonic-Boom Minimization," Journal of the Acoustical Society of America, Vol. 51, No. 2, Pt. 3, 1972, pp. 686-694.

${ }^{6}$ Carlson, H. W., Barger, R. L., and Mack, R. J., “Application of Sonic-Boom Minimization Concepts in Supersonic Transport Design," NASA TN D-7218, 1973.

${ }^{7}$ Graham, D., Dahlin, J., Meredith, K., and Vadnais, J., "Aerodynamic Design of Shaped Sonic Boom Demonstration Aircraft," AIAA-2005-0008, 43 ${ }^{\text {rd }}$ AIAA Aerospace Sciences Meeting and Exhibit, January 10-13, 2005, Reno, NV.

${ }^{8}$ Plotkin, K., Haering, E., Murray, J., Maglieri, D., Salamone, J., Sullivan, B., and Schein, D., "Ground Data Collection of Shaped Sonic Boom Demonstration Aircraft Pressure Signatures," AIAA-2005-0010, 43 ${ }^{\text {rd }}$ AIAA Aerospace Sciences Meeting and Exhibit, January 10-13, 2005, Reno, NV.

${ }^{9}$ Haering, E. A. Jr., Ehernberger, L. J., and Whitmore, S. A., "Preliminary Airborne Measurements for the SR-71 Sonic Boom Propagation Experiment," NASA-TM-104307, 1995, presented at the NASA High-Speed Research Program Sonic Boom Workshop, September 12-13, 1995, NASA CP-3335, 1996.

${ }^{10}$ Meredith, K., Dahlin, J., Graham, D., Haering, E., Malone, M., and Page, J., "Flight Test Measurement and Computational Fluid Dynamics Correlation of F-5E Off-body Pressures," AIAA-2005-0006, 43 ${ }^{\text {rd }}$ AIAA Aerospace Sciences Meeting and Exhibit, January 10-13, 2005, Reno, NV.

${ }^{11}$ Malone, M. B., "Turbulence Model Evaluation for Free Shear Dominated Flows," AIAA-1996-2038, 27 ${ }^{\text {th }}$ Fluid Dynamics Conference, New Orleans, LA, June 17-20, 1996.

${ }^{12}$ Range Commanders Council, "IRIG Serial Time Code Formats," IRIG Standard 200-98, May 1998.

${ }^{13}$ Richardson, N. R., and Pearson, A. O., "Wind-Tunnel Calibrations of a Combined Pitot-Static Tube, Vane-Type Flow-Direction Transmitter, and Stagnation-Temperature Element at Mach Numbers from 0.60 to 2.87," NASA TN D-122, 1959.

${ }^{14}$ Norris, S. R., Haering, E. A., Jr., and Murray, J., "Ground-Based Sensors For The SR-71 Sonic Boom Propagation Experiment," NASA TM-104310, 1995, presented at the NASA High-Speed Research Program Sonic Boom Workshop, September 12-13, 1995, NASA CP-3335, 1996.

${ }^{15}$ Plotkin, K., Martin, R., Maglieri, D., Haering, E., and Murray, J., "Pushover Focus Booms from the Shaped Sonic Boom Demonstrator," AIAA-2005-0011, 43 ${ }^{\text {rd }}$ AIAA Aerospace Sciences Meeting and Exhibit, January 10-13, 2005, Reno, NV.

${ }^{16}$ Haering, E. A., Jr., “Airdata Measurement and Calibration,” NASA TM-104316, 1995, AGARD-AG-300 Vol. 14, Sept. 1995.

${ }^{17}$ Haering, E. A. Jr., “Airdata Calibration of a High Performance Aircraft for Measuring Atmospheric Wind Profiles, ” AIAA Journal of Aircraft, Vol. 29, No. 4, July-Aug. 1992, pp. 632-639.

${ }^{18}$ Haering, E. A., Jr., and Whitmore, S. A., "FORTRAN Program for the Analysis of Ground-Based Radar Data: Usage and Derivations, Version 6.2," NASA TP-3430, 1995.

${ }^{19}$ Plotkin, K. J., "Review of Sonic Boom Theory," AIAA-1989-1105, 12th Aeroacoustics Conference, San Antonio, TX, Apr. 10-12, 1989. 
${ }^{20}$ National Oceanic and Atmospheric Administration, National Aeronautics and Space Administration, and United States Air Force, U.S. Standard Atmosphere, 1976, United States Government Printing Office, 1976.

${ }^{21}$ Plotkin, K. J., and Grandi, F., "Computer Models for Sonic Boom Analysis: PCBoom4, CABoom, BooMap, CORBoom," Wyle Report WR 02-11, June 2002.

${ }^{22}$ Pulliam, T. H., "Artificial Dissipation Models for the Euler Equations," AIAA Journal, Vol. 24, No. 12, 1986, pp. 1931-1940.

${ }^{23}$ Hansen, J. L., Murray, J. E., Campos, N. V., "The NASA Dryden AAR Project: A Flight Test Approach to an Aerial Refueling System," AIAA-2004-4939, AIAA Atmospheric Flight Mechanics Conference and Exhibit, Providence, RI, August 17, 2004. 